\title{
Desarrollo urbano sostenible a partir de un modelo de reactivación para cascos urbanos
}

\section{Urban sustainable development based on the recovery model of urban areas}

\author{
Coralia Rosalía Muñoz-Márquez' \\ Investigadora asociada de la Universidad Tecnológica de El Salvador \\ cmdeco106@hotmail.com \\ Recibido: 29/04/2015 - Aceptado: 19/06/2015
}

\section{Resumen}

Las ciudades se conciben como proveedoras de las condiciones de vida para sus habitantes, y deben enfocarse a ofrecerles espacios cada vez más eficientes en los que las personas puedan realizar sus actividades. Hoy en día, el desarrollo urbano de las ciudades debe orientarse a proveer los espacios y recursos para que sus habitantes puedan alcanzar la sostenibilidad económica, social y ambiental.

Sin embargo, las ciudades de municipios en el interior de El Salvador carecen de condiciones que permitan dicha sostenibilidad. Específicamente, los cascos urbanos o centros históricos de estas urbes suelen observarse abandonados, deteriorados o austeros, lo cual no permite aprovechar el potencial comercial o turístico que pueden ofrecer y genera condiciones de insalubridad e inseguridad que van en detrimento del bienestar de la población.

\section{Abstract}

Cities have been conceived as the suppliers of life for their inhabitants. They should focus on offering more efficient spaces where people can perform their activities. Nowadays, the urban development of cities must be directed to providing such spaces and the resources needed in order for their inhabitants to reach environmental, social and economic sustainability.

However, those cities within El Salvador's municipalities lack the necessary conditions to allow for such sustainability. To be more specific, the urban and historical áreas are usually abandoned, deteriorated or austere. This situation does not allow them to take advantage of the touristic or comercial potential they may offer and it generates insecurity and insalubrity, which is detrimental to the welfare of the population.

Urban renovation, by itself, does not generate sustainable development, but it does constitute a scenario which

Arquitecta, con Maestría en Administración de Empresas, investigadora asociada de la Universidad Tecnológica de El Salvador, con experiencia en investigación en cuanto a construcción, seguridad y salud ocupacional. Correo electrónico cmdeco106@hotmail.com 
La renovación urbana, por sí sola, no genera el desarrollo sostenible, pero sí constituye el escenario que provee los recursos espaciales necesarios para que este ocurra, contribuyendo a mejorar las condiciones de vida de los ciudadanos. Acciones puntuales para mejorar los cascos urbanos pueden ser el punto de partida para marcar la pauta de proyectos posteriores que alcancen otras zonas, brindando mejores condiciones de vida que sean sostenibles en el tiempo.

\section{Palabras clave}

Desarrollo sostenible, desarrollo urbano sostenible, casco urbano, accesibilidad, inclusión, urbanismo verde, generación de actividad económica. provides the necessary spatial resources for this to take place, thus contributing to the improvement of the lifestyle of its citizens. Specific actions to improve urban areas can be the starting point to guide further projects that reach other areas which would offer better sustainable life conditions in time.

\section{Keywords}

Sustainable development, urban sustainable development, urban areas, accessibility, inclusion, green urbanism, economic growth generation

\section{El desarrollo urbano sostenible}

Las ciudades constituyen el hábitat principal del hombre, y como tales deben proveerle lo necesario para un desarrollo integral, constituyéndose como espacios vitales que satisfagan a sus pobladores en los ámbitos económico, social y cultural, entre otros. Si bien, dicho desarrollo depende de diferentes factores y agentes, el esquema urbano es el escenario y el punto de partida para la realización de actividades encaminadas a lograrlo. El ámbito físico espacial impacta la manera en que progresa el ser humano (Corsini, 2007).

Sin embargo, las condiciones que enfrenta la humanidad en el presente siglo requieren que estos hábitats se enfoquen hacia un desarrollo urbano sostenible, el cual se caracteriza por permitir condiciones como la inclusión y la accesibilidad a todos sus habitantes, además de que propicia el crecimiento económico y social de los pobladores con el uso óptimo de los recursos, y lo hace buscando la mayor armonía posible con el medio ambiente.

La inclusión es aquella condición que permite una vivencia de calidad a personas de diferentes grupos de edades, estratos económicos y condiciones físicas, cobrando relevancia la disposición de facilidades para personas con capacidades especiales. Una ciudad incluyente brinda

espacios para la realización de diferentes actividades, como las sociales, religiosas, culturales, así como para niños, jóvenes, adultos mayores, familias, entre otros.

La accesibilidad se caracteriza por el manejo de los espacios públicos donde el peatón se desplaza con libertad, las barreras físicas son mínimas gracias a áreas abiertas o a su continuidad; tampoco hay barreras sociales como la inseguridad y el deterioro, aunque estas dependen también de factores ajenos al ámbito físico espacial (Corsini, 2007).

En cuanto a la sostenibilidad económica, las urbes se orientan a convertirse en sus propias proveedoras de sustento, siempre y cuando esto no sea en detrimento de sus recursos o las condiciones de vida de sus habitantes. Estos desarrollan sus proyectos de vida, sin que necesariamente deban depender de otras ciudades o regiones (Quiroa Laos, 2010).

Finalmente, la construcción de ciudades impacta profundamente los recursos naturales: se elimina la vegetación, se modifica el terreno, se obstruye la infiltración de agua por pavimentos y edificios, se destruyen los hábitats de diferentes especies, además de que se acumulan desechos y se contaminan afluentes de agua (Bazant, 2003). Por ese motivo, se hace necesaria la aplicación del llamado urbanismo verde, el cual contempla 
el aprovechamiento óptimo de las condiciones climáticas, el uso prioritario de energías renovables o tecnologías ambientalmente amigables, la disposición adecuada de desperdicios, la conservación y protección de los recursos hídricos y, además, la consideración de sistemas de transporte que reduzcan la contaminación ambiental (Honles, 2014).

El desarrollo urbano sostenible, entonces, resulta de la aplicación de estas características a los componentes del diseño urbano, con el propósito de consolidar un plan integral que involucre a diferentes sectores; responda a los diferentes requerimientos de la población; haga un uso razonable de los recursos y explote el potencial de desarrollo de las ciudades.

\section{Los cascos urbanos como punto de partida}

La investigación realizada se ha enfocado en iniciar el proceso de desarrollo urbano sostenible a partir del casco urbano de la ciudad. Este espacio es la zona céntrica o el núcleo en torno al cual se ha desarrollado aquella. Regularmente, el casco está constituido por edificios o espacios antiguos: la plaza, la calle principal, la iglesia, el edificio municipal, comercios y casas prominentes. También se le denomina centro histórico (Garayo, 2012).

Los cascos urbanos, por consiguiente, constituyen las áreas más antiguas de la ciudad y, a medida que esta crece, van quedándose en el abandono, presentando características como las siguientes:

- Deterioro de la infraestructura y del patrimonio arquitectónico existente.

- Desorden en los espacios públicos, frecuentemente ocasionado por la invasión de comercios informales e indigentes.

- Dicho desorden trae consigo insalubridad por la inexistencia de desagües y la acumulación de basura y suciedad.

- Del mismo modo, el desorden es propicio para la delincuencia y por eso los espacios se vuelven inseguros.

- Esto provoca un desarrollo limitado, disminuyen las posibilidades de crecimiento de negocios comerciales y otras actividades compatibles con el uso de suelo de los cascos.

- Al no haber posibilidades de crecimiento formal, los espacios quedan en abandono, con lo cual se cierra el círculo porque aquel permite que exista más deterioro y más desorden.

El objetivo general del estudio ha sido establecer un modelo de desarrollo urbano por medio del cual los espacios de los cascos urbanos o centros históricos de diferentes ciudades en El Salvador puedan ser renovados, a fin de abrir oportunidades de desarrollo sostenible a diferentes sectores de las poblaciones locales.

Puede decirse que el punto de origen de la ciudad constituye el punto de partida para su renovación urbana orientada a la sostenibilidad. Y este enfoque no solo obedece al valor histórico que pueda tener, sino a los siguientes motivos:

- El patrón de crecimiento regular de las ciudades se orienta hacia las periferias, lo que provoca el abandono o el desorden en estos espacios. Se hace pertinente la atención de este tipo de espacios.

- Son espacios con vocación turística y comercial que pueden dar pie al desarrollo económico y social.

- Los centros históricos, sobre todo en ciudades en el interior del país, consolidan sus imágenes y sus paisajes urbanos generales.

Por lo tanto, realizar reformas y mejoras en los cascos urbanos puede dar inicio a un desarrollo urbano que en el largo plazo pueda enfocarse a la ciudad completa. Y del mismo modo, las reformas físico-espaciales que se realizaran en aquellos pueden dar lugar, en una forma más eficiente, al desarrollo sostenible de la ciudad en los ámbitos económico, social, cultural y ambiental.

\section{Metodología}

Para la generación del modelo se ha realizado una investigación empírica cualitativa dividida en dos etapas principales. Una etapa de investigación, en la cual se ha incluido la recopilación de criterios teóricos para el diseño urbano sostenible y la observación de modelos aplicados en ciudades de Latinoamérica y Europa, que ha dado como 
resultado la generación del modelo. Y posteriormente, una etapa de aplicación de dicho modelo establecido en tres ciudades elegidas en El Salvador.

La herramienta utilizada para esta etapa fueron fichas de diagnóstico donde se evaluaron las condiciones de deterioro, desorden, inseguridad, insalubridad y abandono; el proceso se ha completado por medio de entrevistas a usuarios de los cascos urbanos, según un formato preestablecido.

\section{Resultados}

El modelo va más allá de una simple remodelación urbana, está concebido como una guía para planificar y ejecutar la reactivación del casco urbano. Aunque su producto será el diseño de la renovación del casco, este es el punto de partida para el desarrollo urbano de toda la ciudad, y sus alcances pueden ir más allá del ámbito físico y espacial, impactando positivamente en lo económico, social, cultural y ambiental.

El proceso parte de un diagnóstico de necesidades y culmina con la elaboración de la propuesta, donde se han aplicado los recursos del modelo para las condiciones específicas de la ciudad. Se recomienda que una entidad gubernamental o municipal dirija las actividades de planificación y ejecución, conformando un grupo multidisciplinario que represente a los diferentes sectores de interés, y que pueda aportar valor tanto al desarrollo del modelo como al diseño urbano final (figura 1).

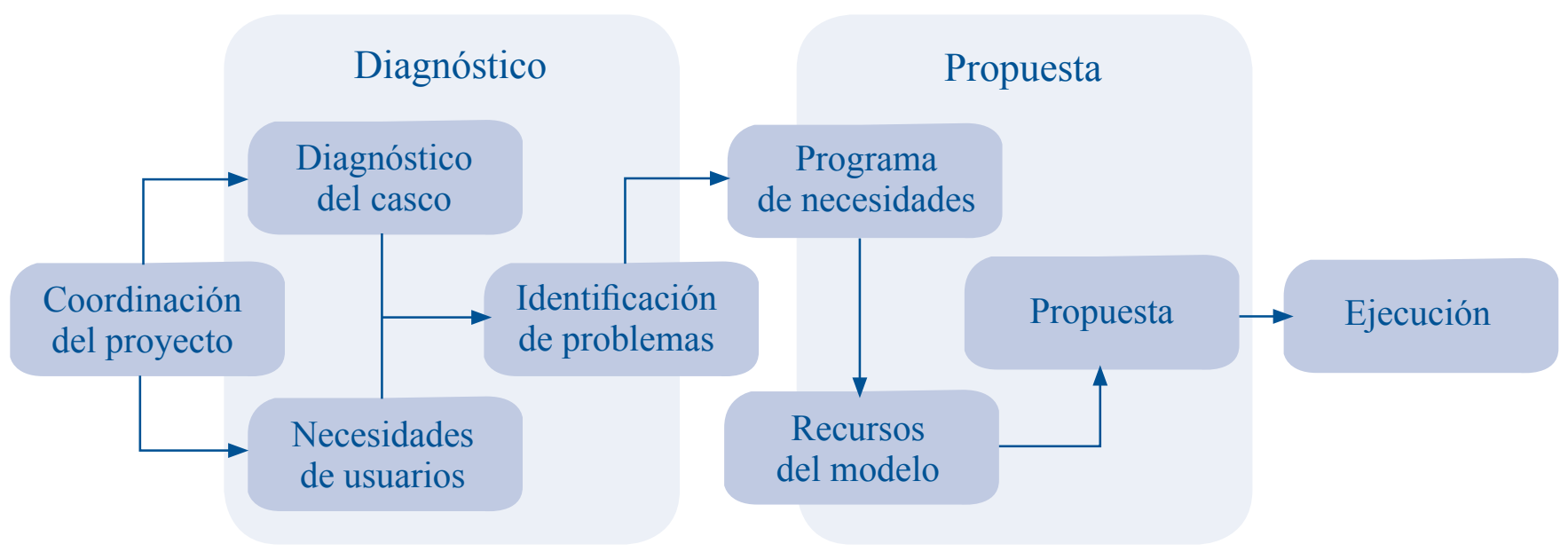

Figura 1.

Proceso de aplicación del modelo de reactivación y desarrollo de cascos urbanos. Fuente: Elaboración propia.

Para el diagnóstico del casco urbano se evalúan sus condiciones, según el deterioro, desorden, desarrollo limitado, abandono, insalubridad e inseguridad que presente, utilizando la ficha de diagnóstico (figura 2). Del mismo modo, se sondean necesidades más específicas en las entrevistas a ciudadanos (figura 3). 


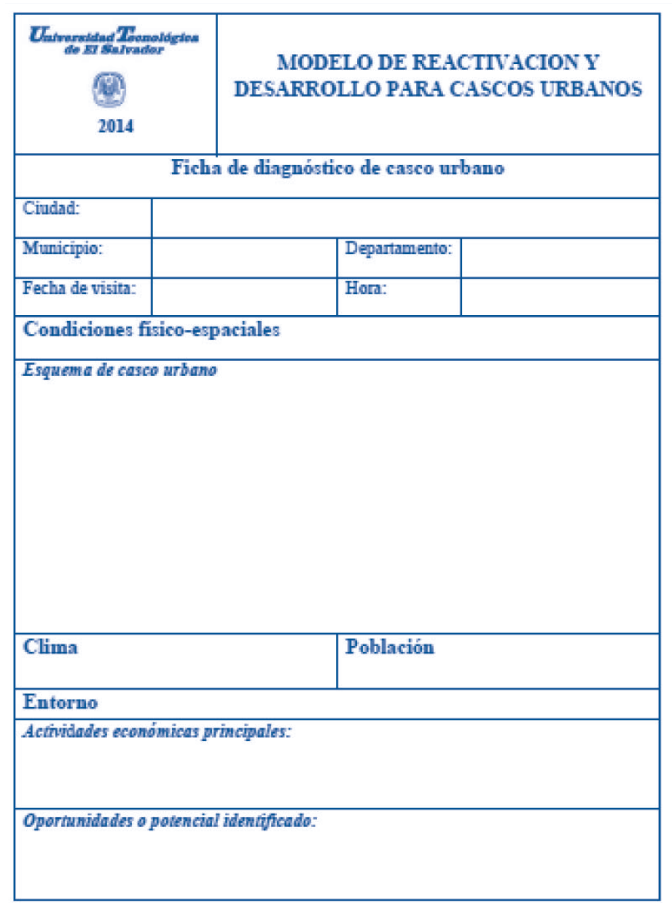

\begin{tabular}{|c|c|}
\hline Inventario de infraestructura & Estado \\
\hline \multicolumn{2}{|l|}{ Edificios de valor histórico } \\
\hline \multicolumn{2}{|l|}{ Otros } \\
\hline Vias de cireulación & Estado \\
\hline \multicolumn{2}{|l|}{ Vehicular } \\
\hline \multicolumn{2}{|l|}{ Peatonal } \\
\hline \multicolumn{2}{|l|}{ Necesidades generales de la población } \\
\hline \multicolumn{2}{|l|}{ Elementos culturales, identidad culfural } \\
\hline \multicolumn{2}{|l|}{ Problemas urbanos } \\
\hline \multicolumn{2}{|l|}{ Deterioro } \\
\hline \multicolumn{2}{|l|}{ Desorden } \\
\hline \multicolumn{2}{|l|}{ Inseguridad } \\
\hline \multicolumn{2}{|l|}{ Insainubridad } \\
\hline \multicolumn{2}{|l|}{ Desarrollo Finitado } \\
\hline Abandone & \\
\hline
\end{tabular}

Figura 2.

Ficha de diagnóstico de casco urbano

Fuente: Elaboración propia.

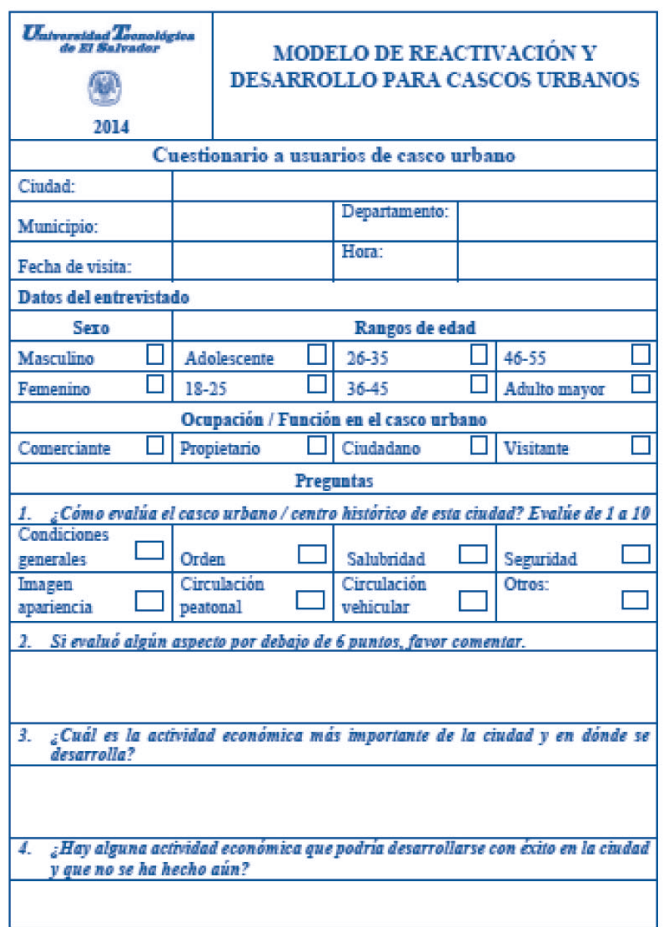

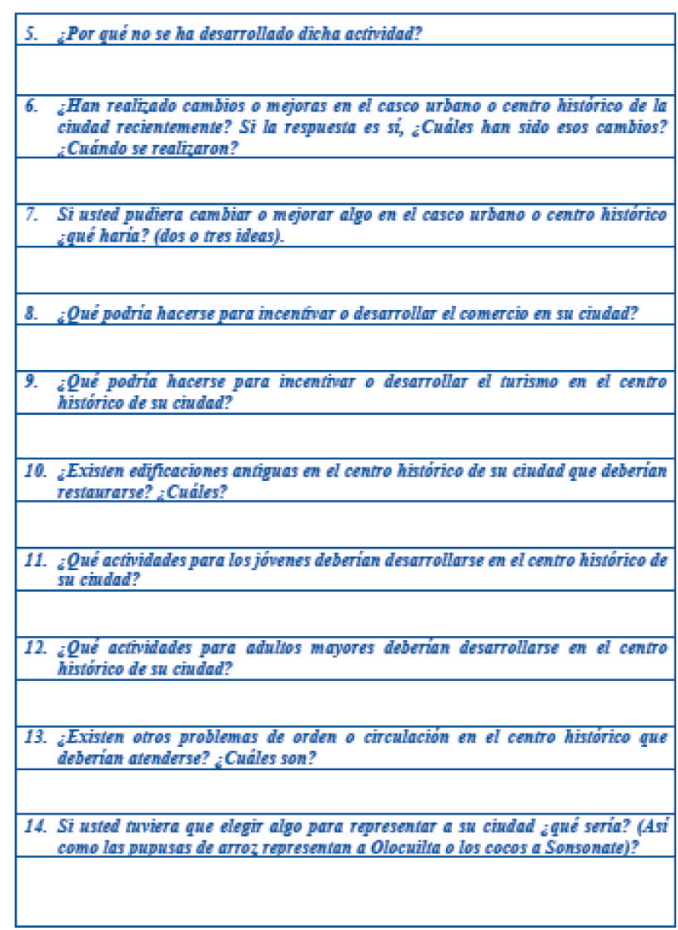

Figura 3.

Cuestionario a usuarios de casco urbano

Fuente: Elaboración propia. 
El diagnóstico se completa por medio de información de referencia adicional, que puede incluir situación socioeconómica de la ciudad, indicadores de desarrollo, datos demográficos y otros similares que faciliten la toma de decisiones y que permitan, sobre todo, identificar los problemas específicos que debe resolver la ciudad en su casco histórico. Tales problemas constituyen la base del programa de necesidades y serán los que tendrán prioridad en ser atendidos en la ejecución del modelo.

\section{Los recursos del modelo}

Estos constituyen las opciones, recomendaciones 0 acciones específicas que se deben implantar, a partir de los criterios de desarrollo urbano sostenible siguientes:

- Accesibilidad e inclusión.

- Peatonalidad: prioridad a la circulación de personas.

- Continuidad y accesibilidad: integración de los espacios públicos por medio de niveles y texturas, además de dar facilidades a personas con capacidades especiales.

- Inclusión: disposición de espacios para necesidades de diferentes grupos sociales.

- Sostenibilidad económica: el modelo se orienta a convertir el casco urbano en un polo de atracción turística y comercial, brindando así ingresos económicos a la población.

- Comercio informal: reordenamiento de las ventas informales y su incorporación a mercados municipales.

- Mercados itinerantes: desarrollo de ventas eventuales organizadas por la municipalidad, donde pequeños y medianos comerciantes pueden ofrecer sus mercaderías yservicios sin tener que invertir en espacios permanentes.

- Comercio formal: acondicionamiento de las áreas públicas y promoción de incentivos municipales para fomentar la inversión privada en comercio formal.

- Desarrollo turístico: desarrollo del potencial turístico que pueda existir en el casco urbano, con el apoyo de programas gubernamentales, inversión privada, aprovechamiento del patrimonio cultural y de comercios formales.

- Armonía con el medio ambiente: un aspecto prioritario para todo proyecto de desarrollo sostenible.

- Impacto ambiental: evaluación del impacto del casco urbano en este aspecto y de la futura renovación.
- Energía renovable: consideración de tecnologías que produzcan ahorro energético.

- Manejo de basura y desperdicios: disposición de infraestructura, instalaciones y otros similares, considerando el reciclaje y optimización de los recursos.

- Recurso hídrico: balance entre las áreas que permiten la filtración de agua y los pavimentos.

- Transporte sustentable: consideración de transportes alternativos dentro del casco urbano o la ciudad en cuestión.

- Diseño urbano: la propuesta física espacial que genere el modelo.

- Imagen: elección de un concepto o estilo que unifique al casco urbano y, además, el diseño de un logotipo representativo que se relacione visualmente con dicho estilo.

- Clima: aprovechar los vientos dominantes, utilizar vegetación para mitigar los rayos solares y otras acciones que consideren el clima del lugar.

- Zonificación: considerar los usos de suelo del casco urbano, teniendo en cuenta que la mezcla de usos complementarios puede resultar provechosa. Por ejemplo, el uso residencial en el casco urbano contribuye a la seguridad del lugar, por la presencia de personas durante horas de la noche.

- Movilidad y circulaciones: ordenamiento de la circulación de personas y vehículos, procurando que no se afecten mutuamente.

- Equipamiento urbano: asegurarse de que el casco cuenta con todo lo necesario para las actividades de comercio y turismo que pretende desarrollar.

- Paisaje: optimización en cuanto al uso de los elementos del paisaje urbano que se observan desde el casco.

- Mobiliario urbano: diseño o adaptación de los accesorios de uso público (bancas, mesas, luminarias, y otros), para que conjuguen con la imagen elegida para el casco urbano.

- Señalética: nomenclatura de calles, señalización para la circulación de vehículos y peatones e información para el turista.

- Pavimentos y texturas: su uso para demarcar espacios y ambientes.

- Patrimonio arquitectónico: evaluación y posible restauración para aprovecharlo dentro de los atractivos turísticos. 
- Iluminación: disposición de las luminarias y otras luces para darle realce al lugar.

- Actividades complementarias: adicional a la renovación física y espacial, el modelo propone actividades que deben ser desarrolladas por la municipalidad y otros agentes que intervengan en el proceso.

- Plan integral: desarrollo de estrategias de desarrollo económico, planes para el uso adecuado de recursos naturales y culturales, participación de productores y gremios locales en la actividad comercial.

- Regulación: establecimiento de reglamentos y ordenanzas necesarios para garantizar que los recursos del modelo funcionen y sean utilizados como fue concebido.

- Opciones de financiamiento: disposición de líneas de crédito accesibles a pequeñas y medianas empresas que puedan participar en la aplicación del modelo.

El modelo ha sido aplicado en forma teórica a tres ciudades de municipios de El Salvador, que fueron elegidas por presentar diferentes características y condiciones, de manera que pudiera evaluarse la factibilidad del modelo. Este ha sido aplicado en su totalidad a cada ciudad elegida. Los elementos más importantes de las propuestas se presentan a continuación.

\section{Salcoatitán, Sonsonate}

Salcoatitán se encuentra en Sonsonate, al occidente del país; su desarrollo económico es escaso si se compara con otras ciudades cercanas como Juayúa o Apaneca, las cuales son destinos turísticos con relativa importancia. La carretera que conduce a estas ciudades atraviesa el casco urbano de Salcoatitán, eso representa una oportunidad pero también una dificultad que se debe superar. Por una parte, el flujo de turistas de dicha carretera puede ser atraído hacia el casco urbano, pero por otra las personas que permanecen en el parque municipal y sus alrededores deben atravesar esta carretera de tráfico pesado para llegar a la iglesia y a las áreas habilitadas para parqueo (figura 4).

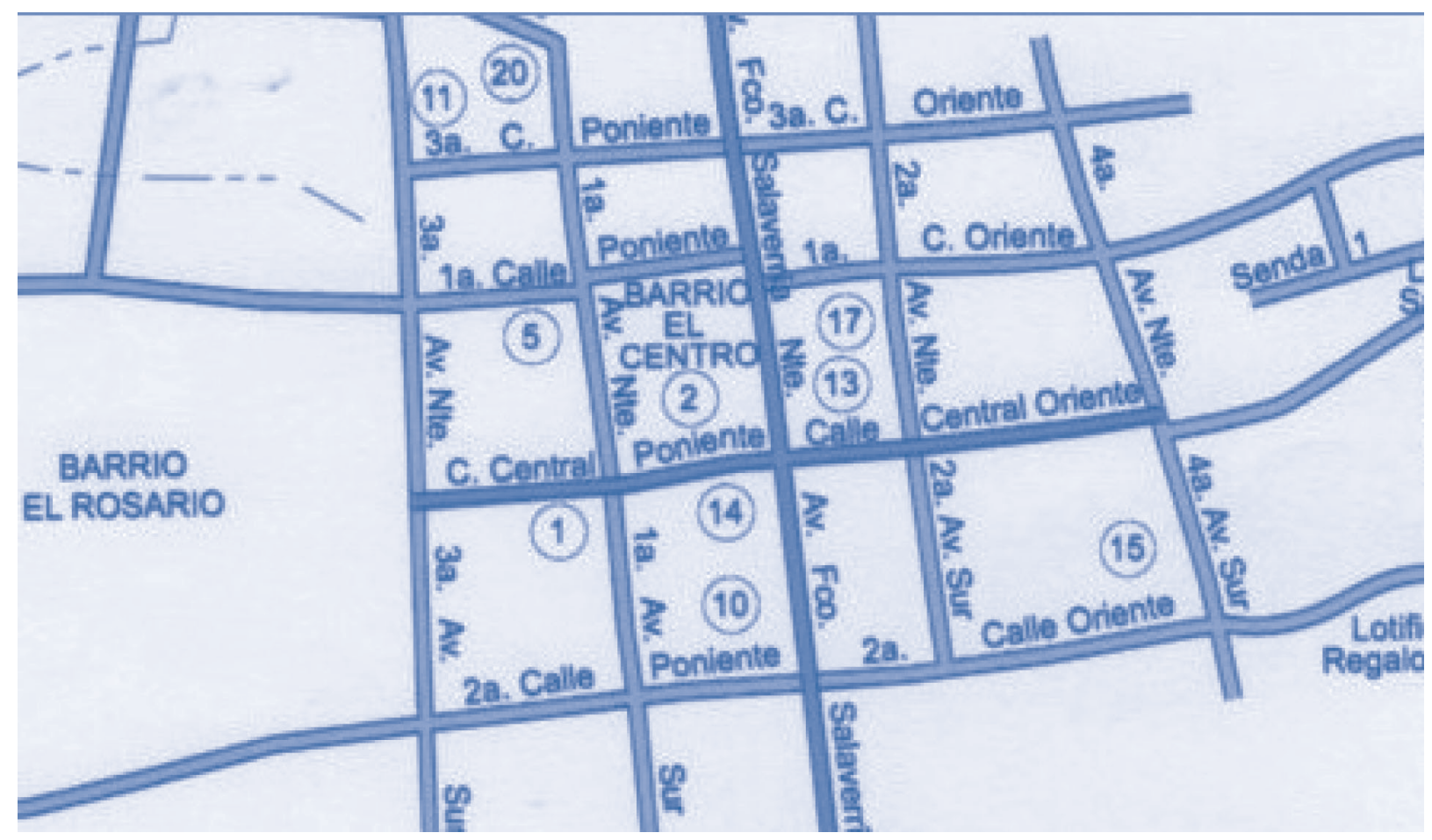

Figura 4.

Croquis de casco urbano de Salcoatitán Fuente: Centro Nacional de Registros de El Salvador. 
El parque posee mobiliario deteriorado y cierta mezcla de estilos en su diseño, pero está arborizado y constituye un espacio fresco y agradable que invita a permanecer en él. En una de las calles laterales se mantienen ventas de platillos típicos y artesanías, en instalaciones provisionales; carecen de desagües y servicios formales de energía eléctrica y agua potable. Al momento de realizar la investigación, el municipio había iniciado la construcción de la Plaza del Turismo. Según los ciudadanos entrevistados, esta edificación albergaría locales comerciales para darle un espacio adecuado a las actividades que se encuentran

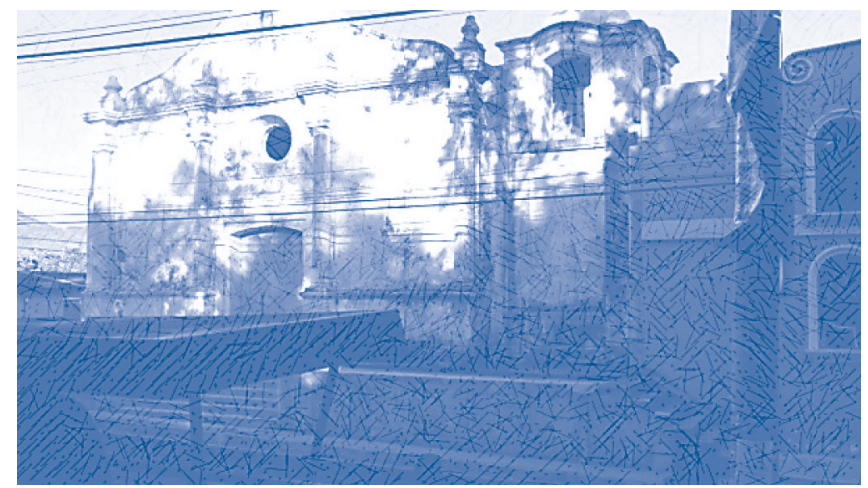

en la calle, contribuyendo así con el desarrollo económico de la ciudad y el aprovechamiento del potencial turístico que posee.

El casco cuenta con dos lugares con potencial turístico. Uno de ellos es la iglesia San Miguel Arcángel, patrimonio arquitectónico de la época colonial, que resultó dañada en los terremotos de 2001, por lo que se construyó una réplica a uno de sus costados. El otro es el museo de la imprenta, una iniciativa privada de valor cultural (figura 5).

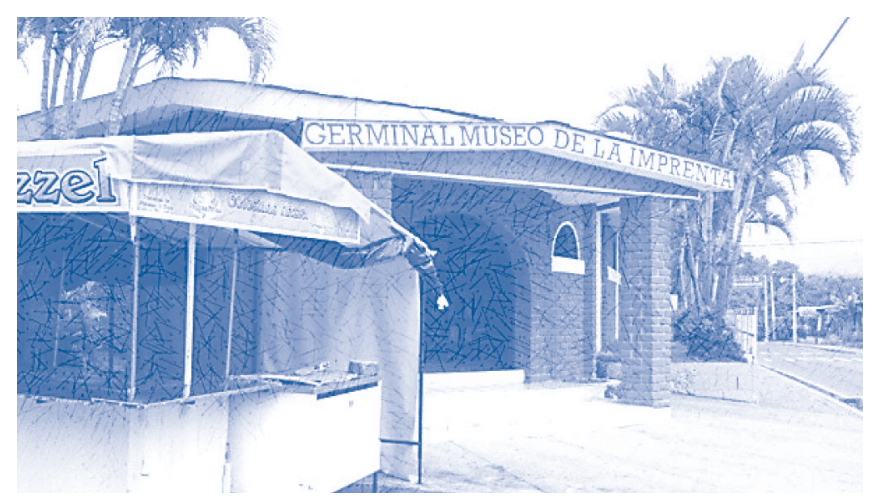

Figura 5.

Iglesia "San Miguel Arcángel" y el Museo de la Imprenta Fotografías: Coralia Muñoz, Salcoatitán, Sonsonate, septiembre de 2014.

La imagen propuesta para la ciudad de Salcoatitán se basa en su toponimia, que proviene de la deidad de la mitología indígena Quetzalcoatl, representada como una serpiente emplumada. Dicho elemento se ha representado como un mosaico, debido a que esta es una decoración que se ha aplicado tanto en la iglesia como en otros lugares de la ciudad, producto de una artista local. El elemento de Quetzalcoatl se ha utilizado para los diseños del mobiliario urbano y sería la línea arquitectónica que se ha de seguir en la remodelación del parque, donde, aunque se mantiene el esquema tradicional, se le ha añadido elementos curvos que asemejan a la serpiente mítica (figura 6).
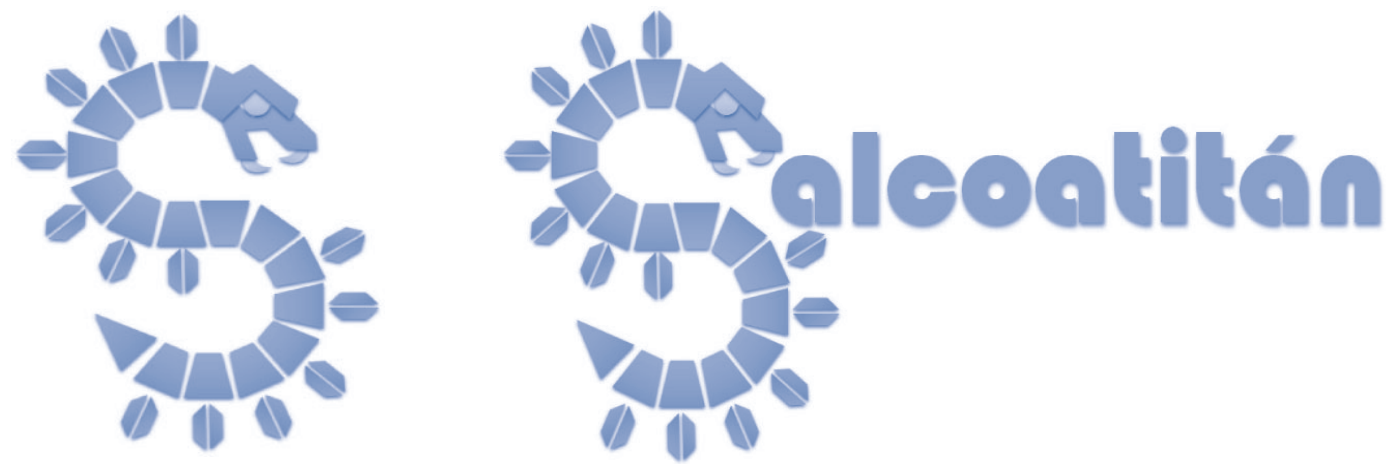

Figura 6.

Logotipo representativo de Salcoatitán: mosaico de Quetzalcoatl Fuente: Elaboración propia. 
El modelo aplicado pretende convertir el casco urbano en un complejo con equipamiento comercial y turístico, con una propuesta de elementos recreativos que pueden atraer visitantes y generar así ingresos económicos para la población, promoviendo el crecimiento de pequeños y medianos empresarios y creando fuentes de empleo.
El diseño del casco incluye el desarrollo de un área peatonal en las calles en torno al parque, las cuales se han demarcado con texturas. Estas no pueden unificarse con la iglesia, pero su ambientación permitirían actividades comerciales que propicien la circulación de personas. Las líneas curvas emulan la imagen de Quetzalcoatl (figura 7).

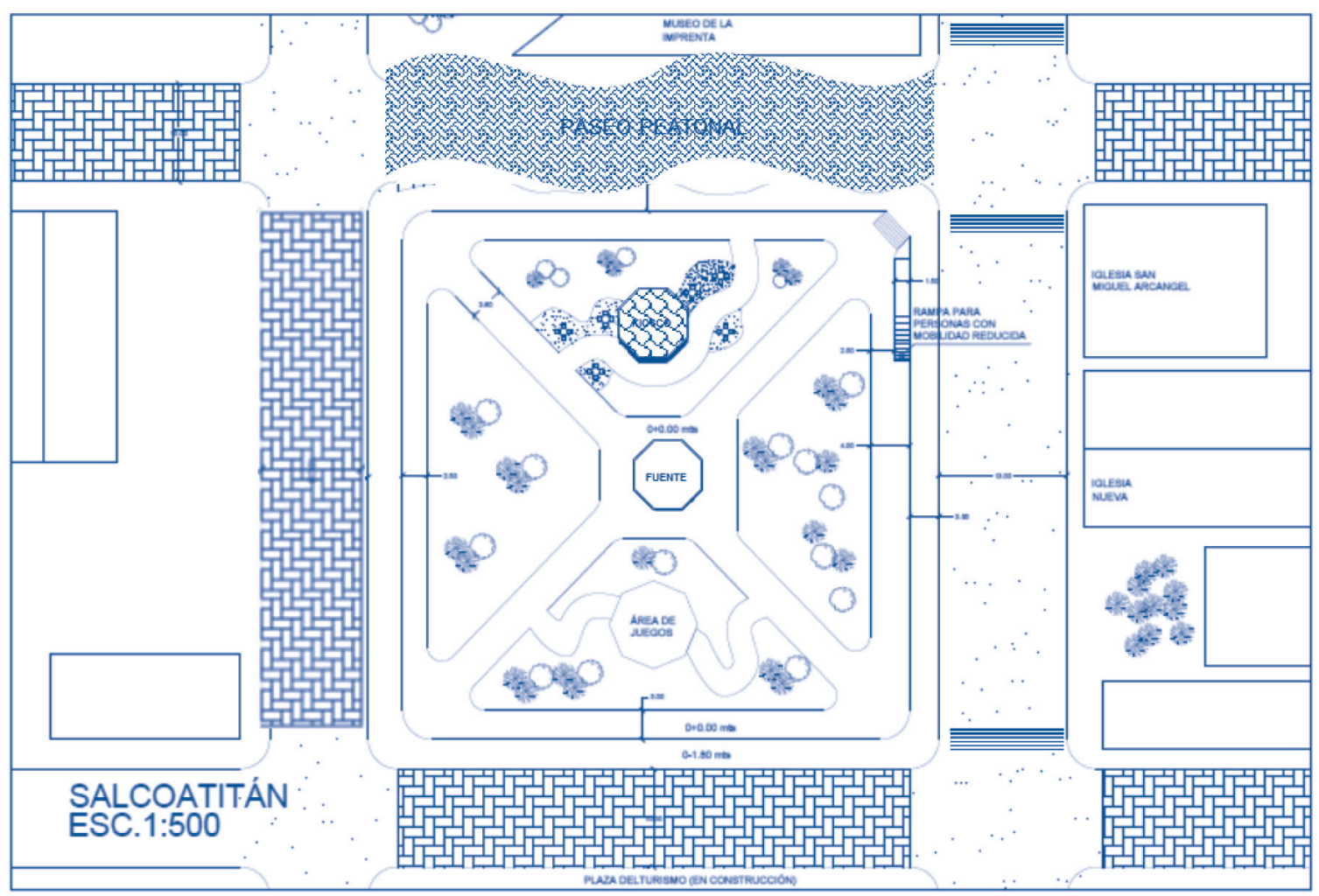

Figura 7.

Planta arquitectónica del casco urbano de Salcoatitán

Fuente: Elaboración propia.

Se recomienda la promoción turística del Museo de la Imprenta que, aunque no tiene una relación directa con la historia de la ciudad, constituye un lugar que aporta valor a la cultura general. Del mismo modo, debe considerarse la restauración de la iglesia colonial no solo por su valor histórico y patrimonial, sino porque puede convertirse en un destino turístico, contando con una administración adecuada.
Para el parque se han propuesto modificaciones que incluyen un quiosco, senderos curvos, áreas de juegos y de mesas; la forma irregular puede adaptarse a las áreas que no tienen vegetación y permiten disfrutar el ambiente bajo los árboles. El mobiliario del parque se ha diseñado utilizando formas curvas, según estilo elegido para la ciudad y se han incorporado detalles con el logotipo de Quetzalcoatl (figura 8). 

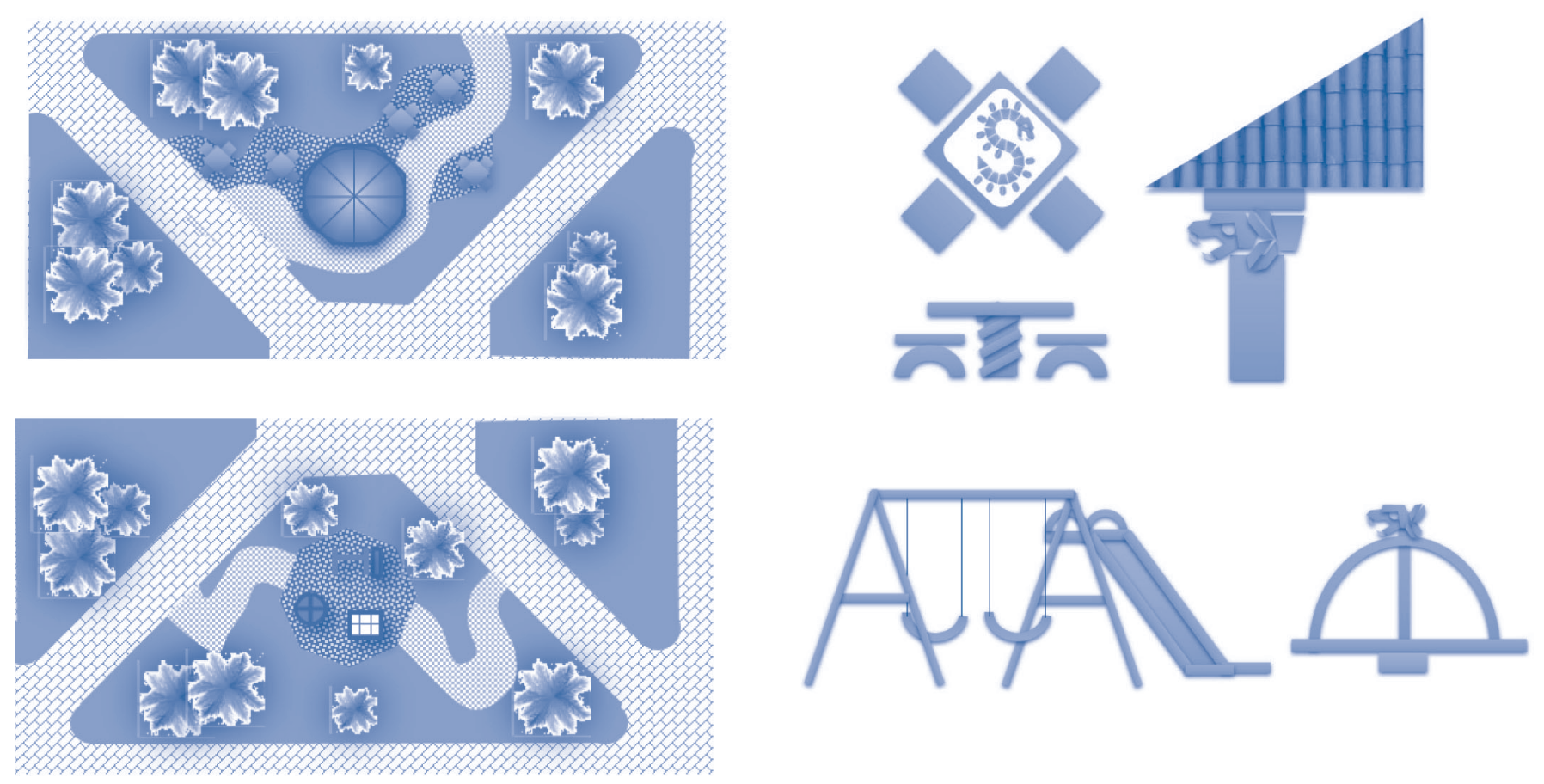

Figura 8.

Detalles de la remodelación y el mobiliario del parque municipal Fuente: Elaboración propia.

La calle aledaña al Museo de la Imprenta se ha concebido como un paseo peatonal utilizando curvas y texturas que hacen referencia a la imagen de Quetzalcoatl, ambientado con decoraciones alusivas puede ser un excelente punto de atracción para los visitantes y, por consiguiente, dar lugar a la generación de ingresos económicos (figura 9). Es posible que los comerciantes que actualmente se ubican en esa calle formen parte de la Plaza del Turismo, pero es recomendable que se mantengan los mercados itinerantes, como una oportunidad para pequeños empresarios que aún no pueden pagar locales permanentes.

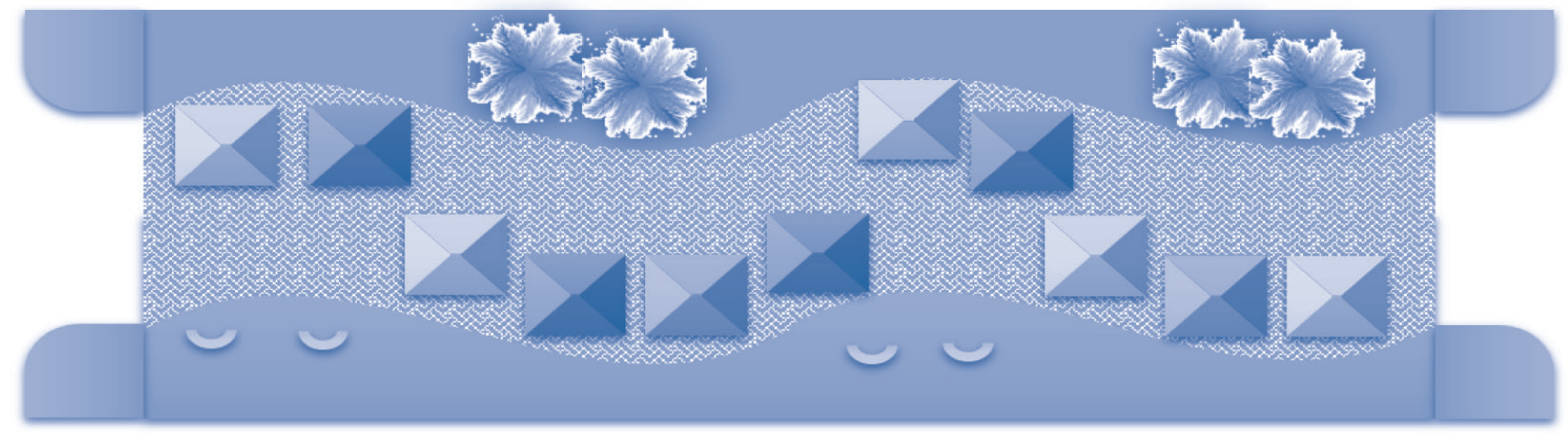

Figura 9.

Paseo peatonal

Fuente: Elaboración propia. 
Para poder facilitar el cruce de peatones sobre la avenida principal, se propone la ubicación de cambios de nivel que permitan reducir la velocidad de los vehículos que circulen por la carretera. Este cambio de nivel es más conveniente que los túmulos, porque estos requieren que el vehículo se detenga en forma más brusca, lo cual es contraproducente en una vía donde hay tráfico con mucha velocidad. Otra opción que puede resultar práctica es desviar la circulación por otras calles, como las que rodean la iglesia: la calle central oriente, la $2 .^{\text {a }}$ Avenida Norte y la $1 .{ }^{\text {a }}$ Calle Poniente. En la actualidad, estas vías carecen de pavimentación y pueden resultar estrechas para el paso de transporte pesado (figura 10).

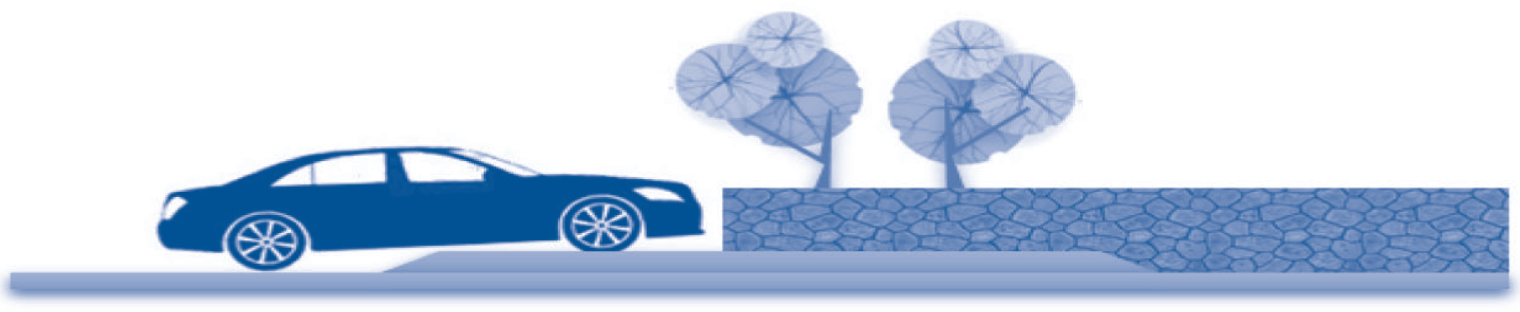

Figura 10.

Cambios de nivel de avenida principal para disminuir la velocidad de los vehículos Fuente: Elaboración propia.

El mobiliario urbano brinda unidad a todo el casco urbano, por lo que es importante que mantenga unidad en su diseño y estilo, y que esté relacionado con el logotipo y la imagen elegidos para el casco urbano (figura 11). Por ese motivo, se han elegido materiales como el concreto, que, por ser pétreo, conjuga muy bien con las referencias a las efigies de piedra de las deidades precolombinas. Las formas aplicadas son de línea simple, sin rebuscamientos, con detalles curvos. Varios elementos han sido decorados con mosaicos con el logotipo de Quetzalcoatl. Los basureros están agrupados de tres en tres para promover el reciclaje, en forma de tubo, sin patas ni soportes, tampoco tienen tapaderas para que sean más resistentes al uso o por el vandalismo.
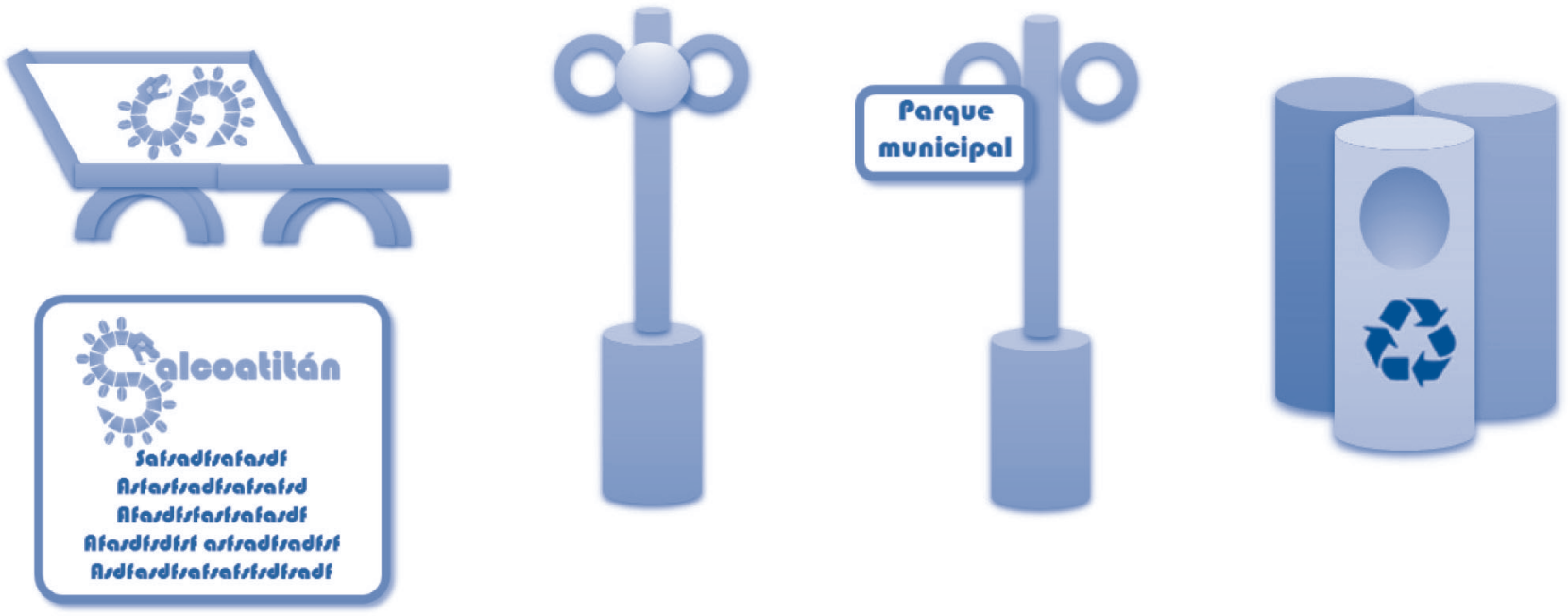

Figura 11.

Mobiliario urbano. Banca, rotulación, luminaria, nomenclatura y basureros

Fuente: Elaboración propia. 
En cuanto al diseño de la iluminación, se deben ubicar las luminarias en las aceras a manera de darle total unidad a los alrededores del parque. Dentro de este también debe ubicarse este tipo de lámparas, sobre todo porque se están desarrollando espacios dentro de lo que antes eran jardines cerrados, y es necesario prevenir actos delincuenciales. Las luces de conducción accionadas por energía solar son adecuadas para los senderos de las áreas de mesas y de juegos. La iglesia, por su parte, amerita luz de realce para terminar de acentuar su presencia como el elemento más importante del paisaje urbano, lo cual puede lograrse con reflectores que acentúen las formas arquitectónicas desde la base (figura 12).
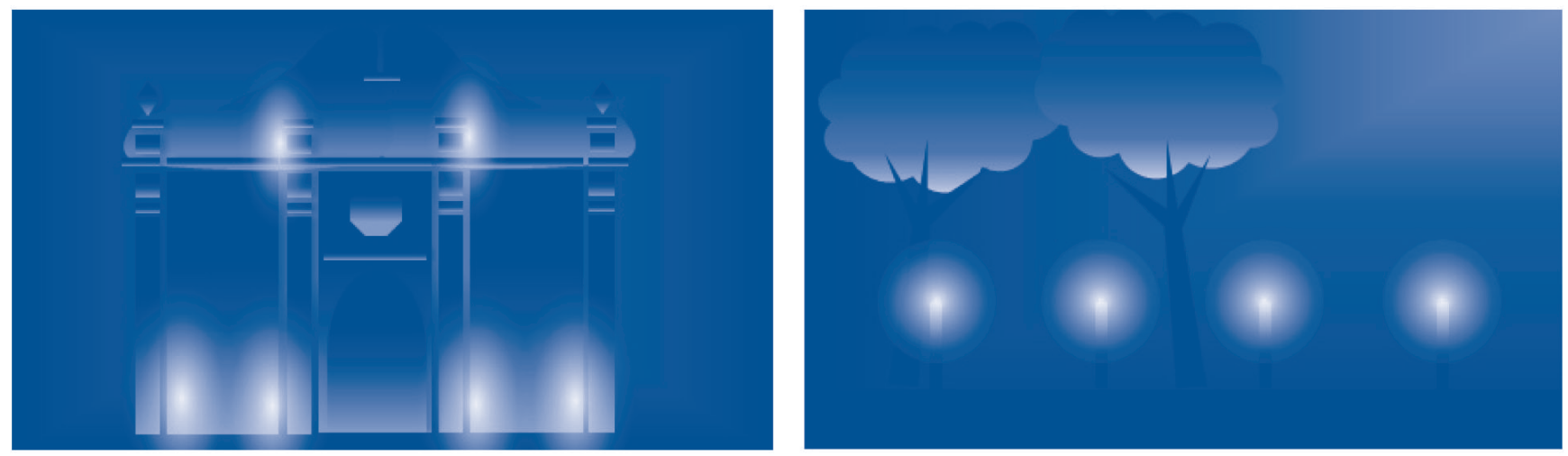

Figura 12:

lluminación para realzar la iglesia y luces de conducción en el parque municipal Fuente: Elaboración propia.

\section{Santa María Ostuma, La Paz}

Santa María Ostuma es una ciudad del departamento de La Paz, ubicada a unos 30 minutos de la carretera a Zacatecoluca. Esta ciudad ha recibido cierto reconocimiento del público a raíz del festival de la piña, evento turístico realizado desde 2004 con una oferta de gastronómica y artesanal que gira en torno a esta fruta, cuyo cultivo es una de las actividades económicas más productivas en la zona. A pesar de esto, la ciudad se encuentra alejada de las carreteras principales y el flujo turístico, lo cual es uno de los vitales retos que debe enfrentar la aplicación del modelo (figura 13).

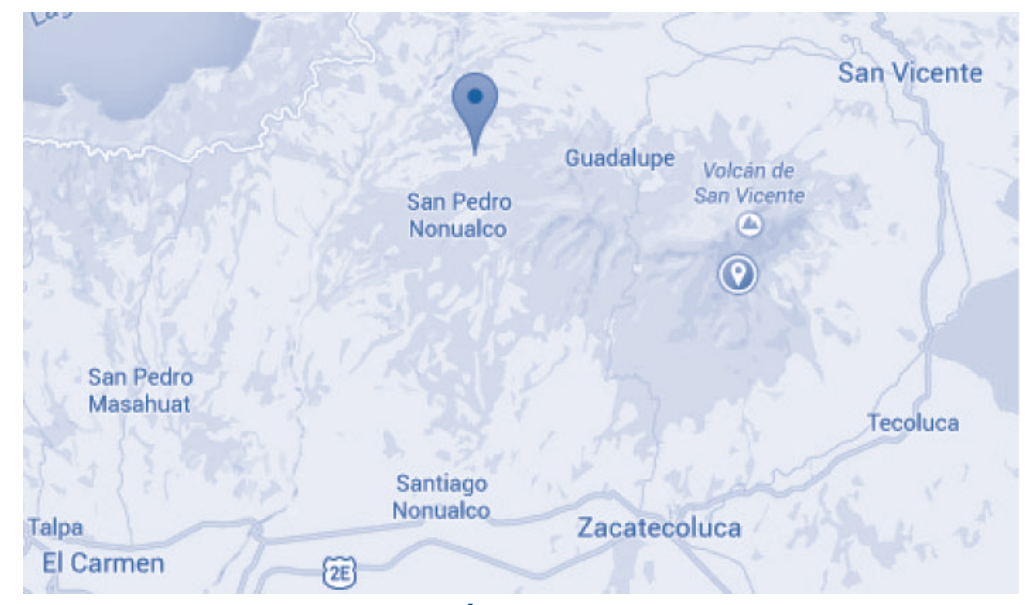

Figura 13.

Mapa de ubicación de Santa María Ostuma

Fuente: Google Maps. Mapas e información de uso público. 
Otra condicionante que se debe tomar en cuenta es que la actividad comercial es limitada. Y es únicamente en actividades eventuales como el festival mencionado que se logra flujo turístico y comercio. La actividad económica principal es más bien la agrícola, por lo que la ciudad carece de otras fuentes de empleo. Se cuenta con un instituto de educación superior muy bien equipado, pero los jóvenes que finalizan sus estudios deben desplazarse a otros lugares para obtener otro tipo de puestos de trabajo.

Debido a la geografía montañosa, la ciudad se ha desarrollado linealmente a los costados de la carretera principal que la atraviesa totalmente y que culmina en una especie de $Y$ donde se encuentran la iglesia parroquial y algunos espacios comerciales. Allí se ubica el casco urbano.
La alcaldía municipal está a unas cuadras de este punto y no existe un parque municipal como tal, aunque la iglesia tiene una zona verde equipada y ambientada estéticamente que cumple la función como espacio recreativo, además de que se aprovecha la vista panorámica.

La réplica del templo colonial, la iglesia parroquial actual, resultó dañada en el terremoto del 2001, pero posee la misma arquitectura y estética que la original, siendo el punto focal del casco urbano. Posiblemente no tiene el mismo valor histórico, pero sí resulta emblemática para toda la ciudad. Tanto en la iglesia como en la calle principal se observan elementos decorativos relacionados con la piña, lo que confirma la importancia del festival antes mencionado (figura 14).
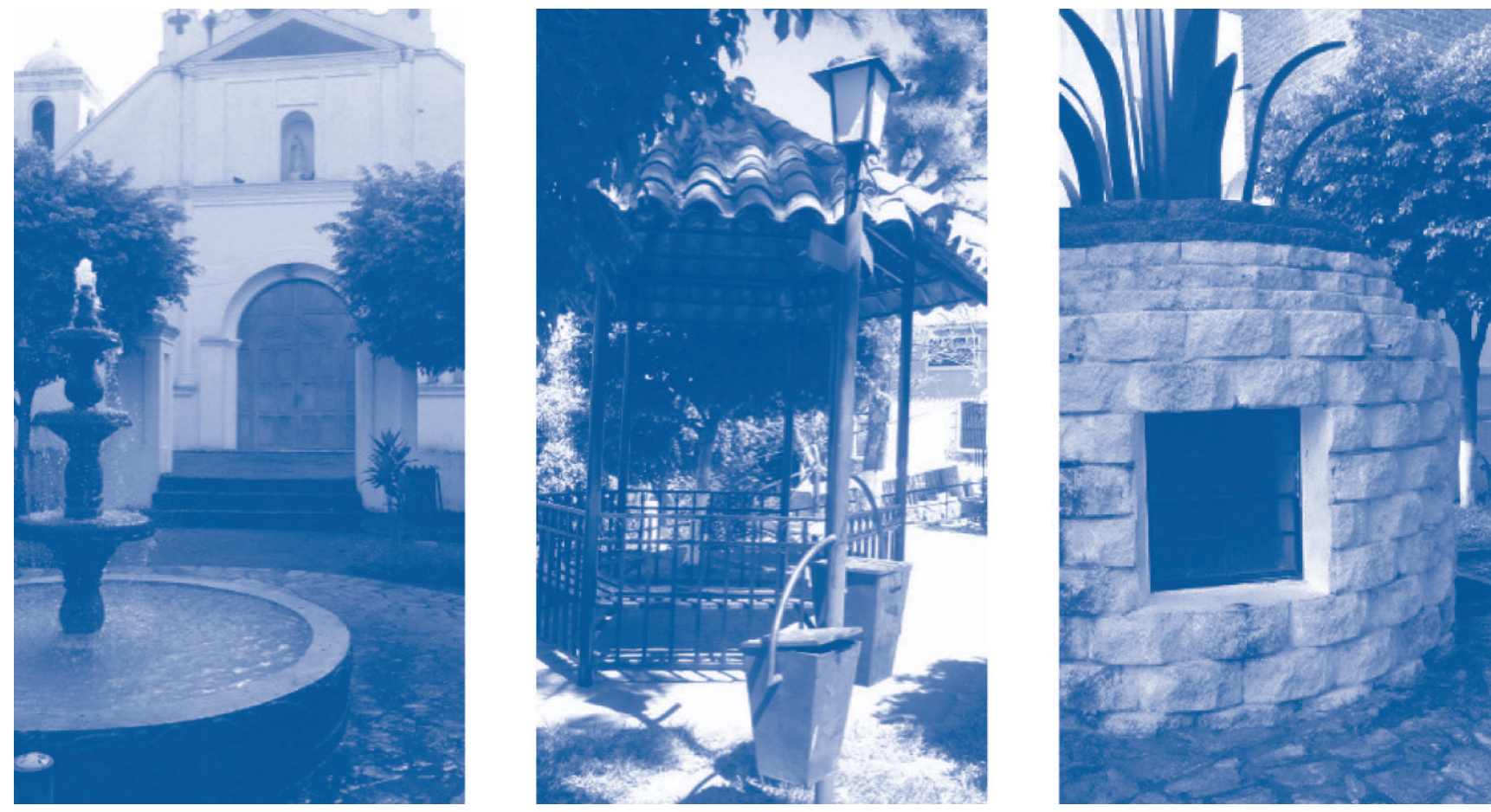

Figura 14.

Iglesia parroquial y detalles del casco urbano de Santa María Ostuma

Fotografías: Coralia Muñoz, Santa María Ostuma, La Paz, septiembre de 2014. 
La aplicación del modelo, entonces, planteó condiciones diferentes y obstáculos a los que se han encontrado en Salcoatitán, por ejemplo. Ciertamente, el casco urbano no aportará una solución total para la falta de actividad comercial, pero puede tomarse como un punto de partida. También es necesario comprender que las acciones

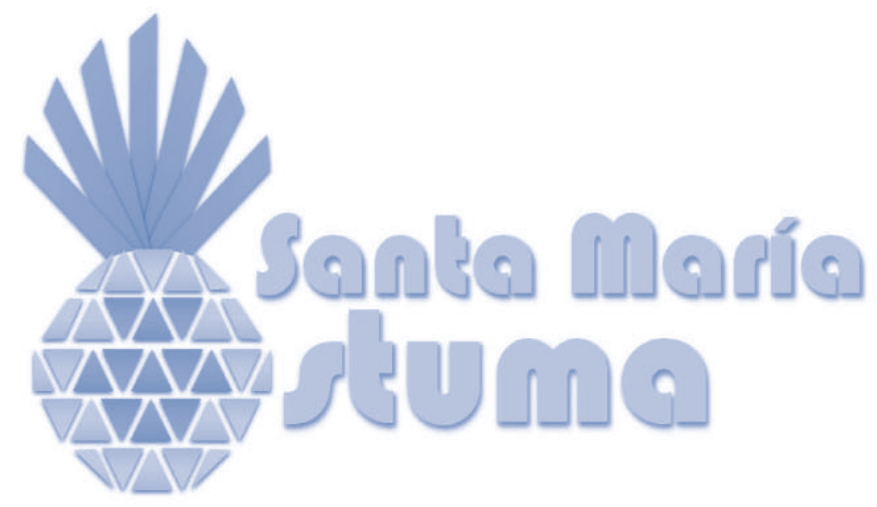

respecto al casco urbano deben ir acompañadas de iniciativas locales o con apoyo gubernamental que impulsen el desarrollo comercial de esta ciudad.

Para la aplicación del modelo se ha elegido y la imagen de la piña para el logotipo el estilo colonial de la iglesia (figura 15)

Figura 15.

Logotipo de Santa María Ostuma: la piña. Imagen de la fachada de la iglesia

Fuente: Elaboración propia.

El diseño del casco urbano se muestra en la figura 16. En términos generales, se propone establecer una especie de centro de la ciudad, brindándole textura a las vías de circulación y dándole valor con dos espacios remodelados: la Plaza de la Cultura y el Merendero Ostumeño.

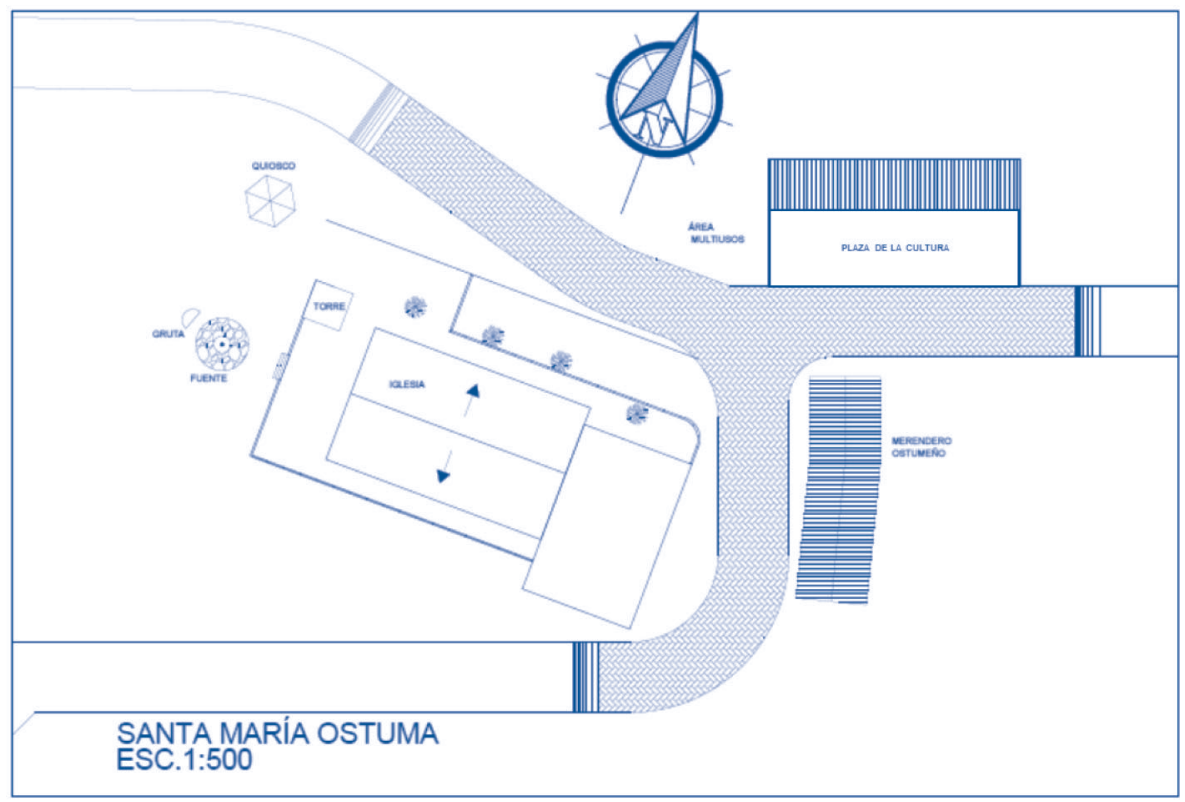

Figura 16.

Planta arquitectónica del casco urbano de Santa María Ostuma Fuente: Elaboración propia. 
Se ha propuesto remodelar el Merendero Ostumeño para hacerlo más atractivo comercialmente e integrarlo a la imagen elegida para el casco urbano. Los cambios consisten en sustituir la pared exterior por arcos de medio punto y columnas robustas, similares a las de la iglesia parroquial, dejando esos espacios abiertos para que quienes permanezcan en su interior vean el panorama del casco urbano y aprecien más la iglesia; la renovación se acentúa con tejas decorativas en el techo. La remodelación no implica una ampliación de locales, sino el acondicionamiento de la estética del inmueble, para hacerlo comercialmente más atractivo y para unificar su imagen al del resto del casco (figura 17).
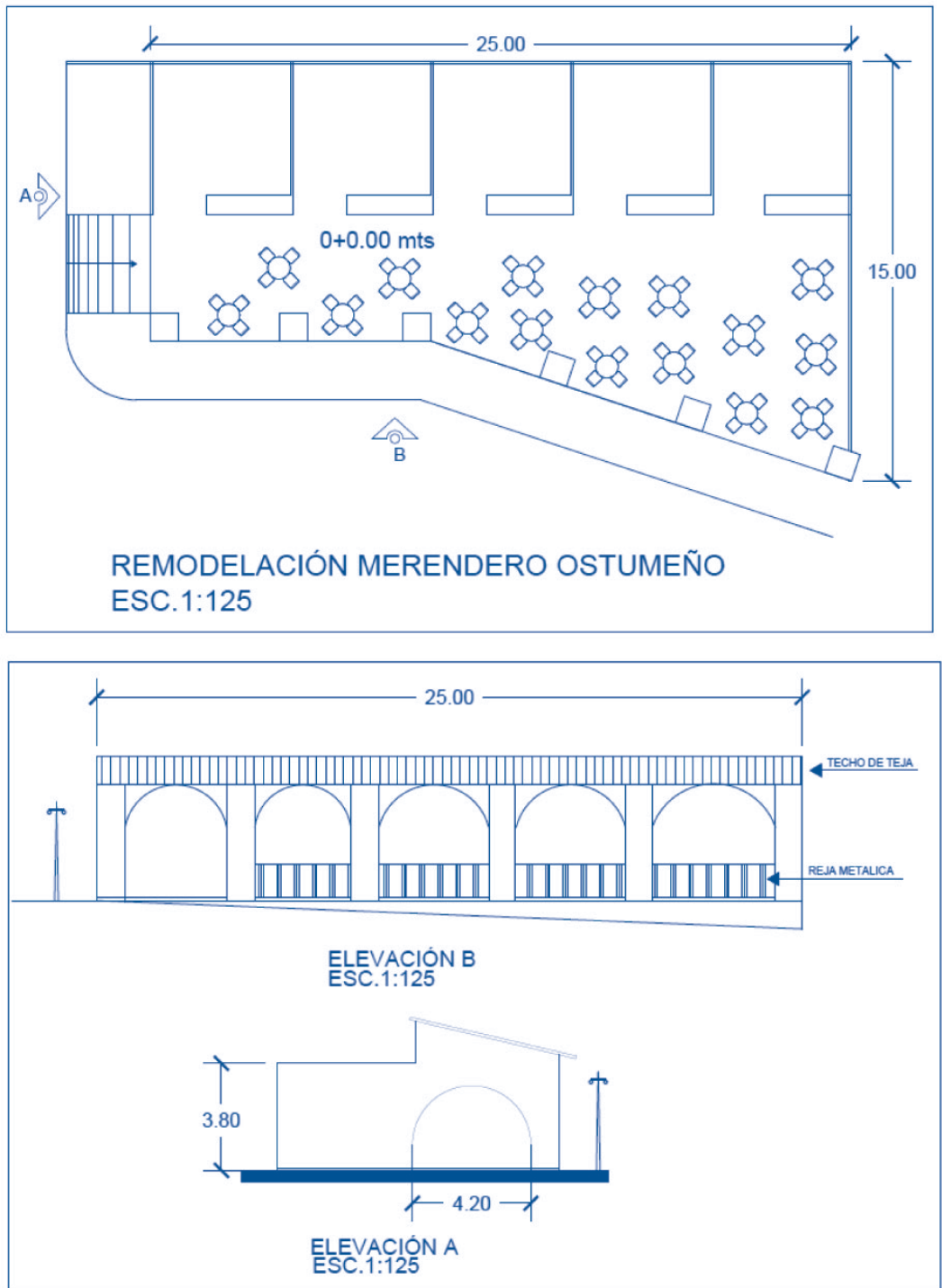

Figura 17.

Remodelación de Merendero Ostumeño

Fuente: Elaboración propia. 
El espacio nuevo que se propone es la Plaza de la Cultura, ubicada en la actual cancha de basquetbol bajo techo. Para ello se ha abierto el espacio, creando una plazoleta frente a locales abiertos que pueden servir para ubicar mercados itinerantes. En el frente de esta se han ubicado columnas similares a las del muro de la iglesia parroquial. Para brindar continuidad en el diseño del espacio urbano y el piso se propone que sea cubierto con baldosa de barro. Los locales son abiertos, con arcos y techos de teja para enfatizar más su carácter colonial. En uno de los extremos se ha ubicado una torre que funciona como mirador y que mantiene relación con la torre frente a la iglesia parroquial para dar más unidad al conjunto urbano. El desnivel entre la plazoleta y la calle se ha enchapado con piedra natural.

La Plaza de la Cultura está considerada para alojar mercados itinerantes en forma periódica y evitar que algunas de las ventas invadan las calles, generando desorden. También está diseñada para que en ella se desarrollen eventos culturales ubicando una tarima en una de sus esquinas. Se asume que el público se ubicaría en la calle principal, cerrando el paso de vehículos temporalmente (figura 18).
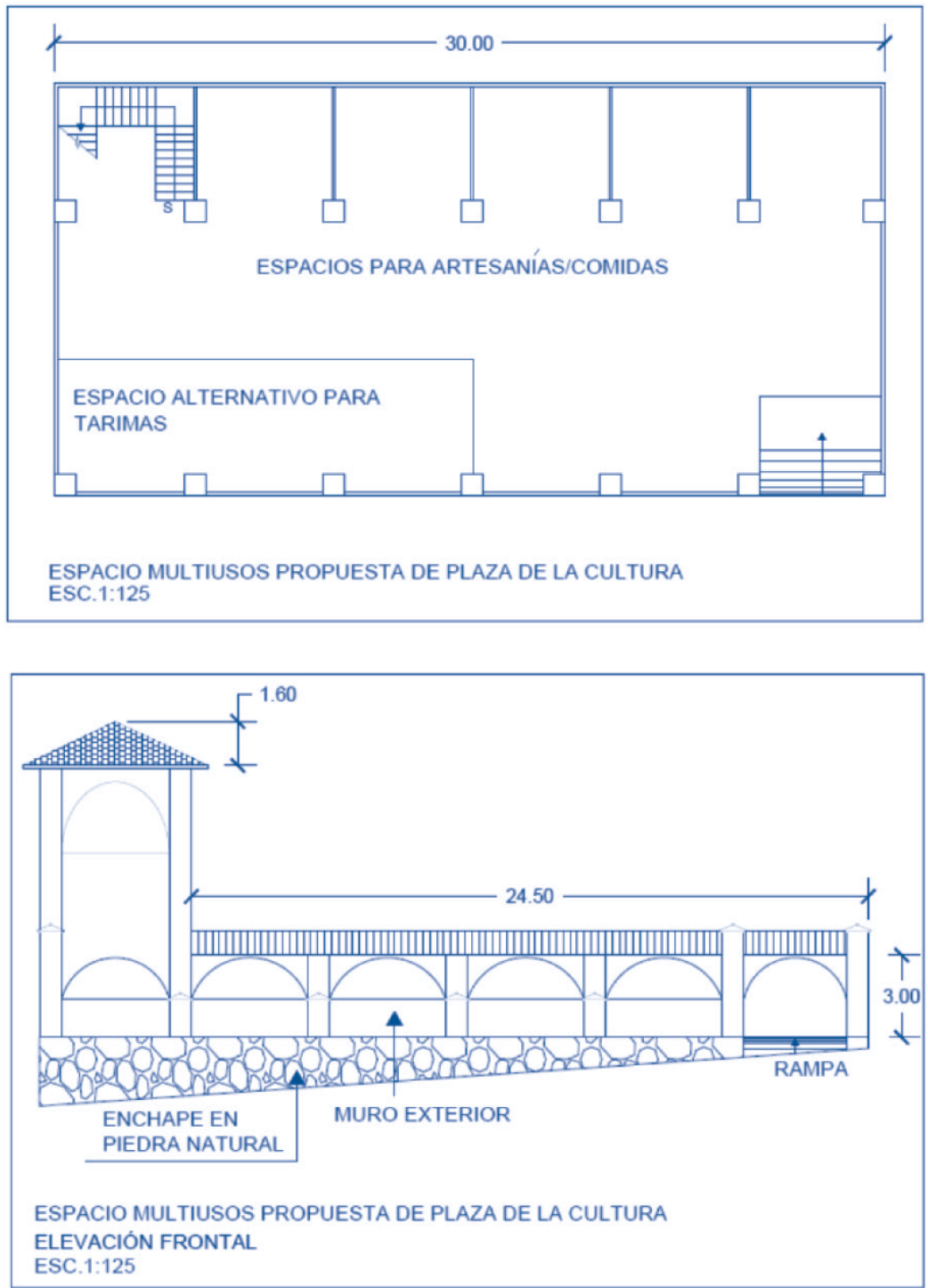

Figura 18.

Propuesta de Plaza de la cultura

Fuente: Elaboración propia. 
La atracción de visitantes no puede provenir del diseño urbano por sí solo, sino que debe haber un esfuerzo conjunto de la municipalidad, las entidades gubernamentales y los empresarios para lograrla. Y debe tenerse en cuenta que el turismo no necesariamente podría ser una actividad diaria, por lo que debe buscarse otra opción que inyecte recursos diariamente. $Y$ en ese caso, el presente estudio recomienda una acción de crear redes de comercio entre Santa María Ostuma y otras poblaciones cercanas, proponiendo un desarrollo más regional, que beneficie y responda a las necesidades locales.
Debe considerarse que en esta ciudad la circulación vehicular está en conflicto con la circulación peatonal y que las acciones que se deben tomar tendrían que considerar una ruta alternativa para los buses y el tráfico hacia San Isidro cuando se realizan actividades en el casco urbano. Pero esa sería una inversión bastante alta por parte de la municipalidad, por lo que en una primera etapa se deben realizar acciones para generar mayores ingresos económicos, y posteriormente debería considerarse la opción de una ruta alterna (figura 19).

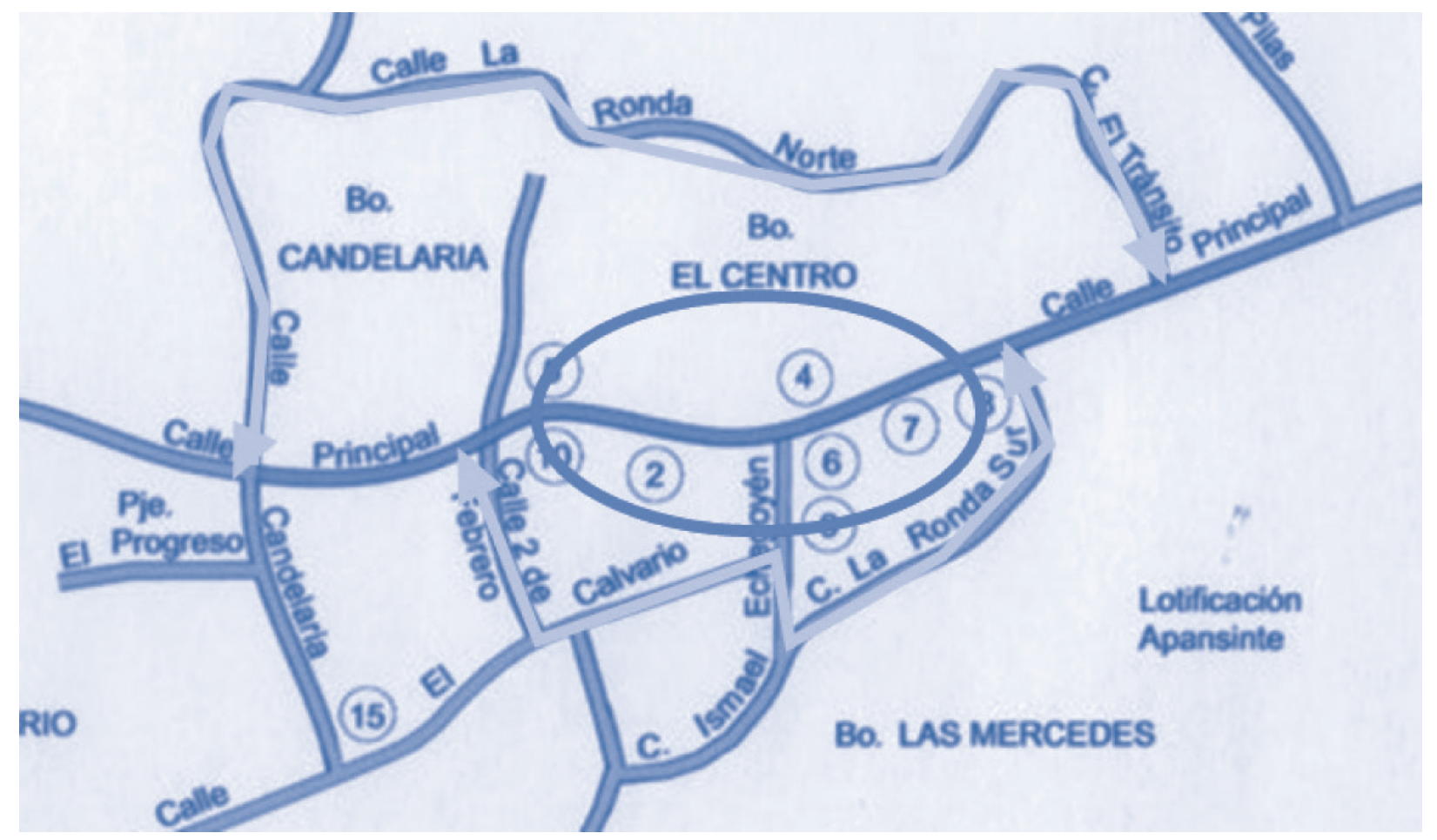

Figura 19.

Posibles rutas alternas para desarrollar circulación vehicular

Fuente: Elaboración propia sobre información del Centro Nacional de Registros.

Este punto cobra importancia porque el turismo que se pretende generar implica mayor flujo de vehículos y autobuses hacia la ciudad. Para aligerar la carga vehicular sobre el casco urbano, cuando se realicen actividades peatonales, puede optarse también por transporte alternativo, como bicicletas. Eso implica el establecimiento de un servicio de alquiler de bicicletas, que esté ubicado antes del inicio del área del casco, para que las personas o visitantes que así lo deseen estacionen sus vehículos antes de ingresar al casco, y lo recorran usando las bicicletas. Esta opción es otra fuente de generación de ingresos. Posiblemente no todos los visitantes optarán por usarla, pero sí puede contribuir a bajar carga vehicular.

La calle principal deberá utilizarse para circulación de vehículos y personas en forma alterna; y de optarse por el servicio de bicicletas, deben incluirse diferencias en texturas según lo siguiente: 
- Las texturas se aplicarán en la calle principal, en torno a la iglesia parroquial y en una parte de la Calle "Ismael Echegoyén", frente al Merendero Ostumeño.

- Las aceras se mantendrán en la misma dimensión actual y se utilizarán para el paso de peatones, exclusivamente.

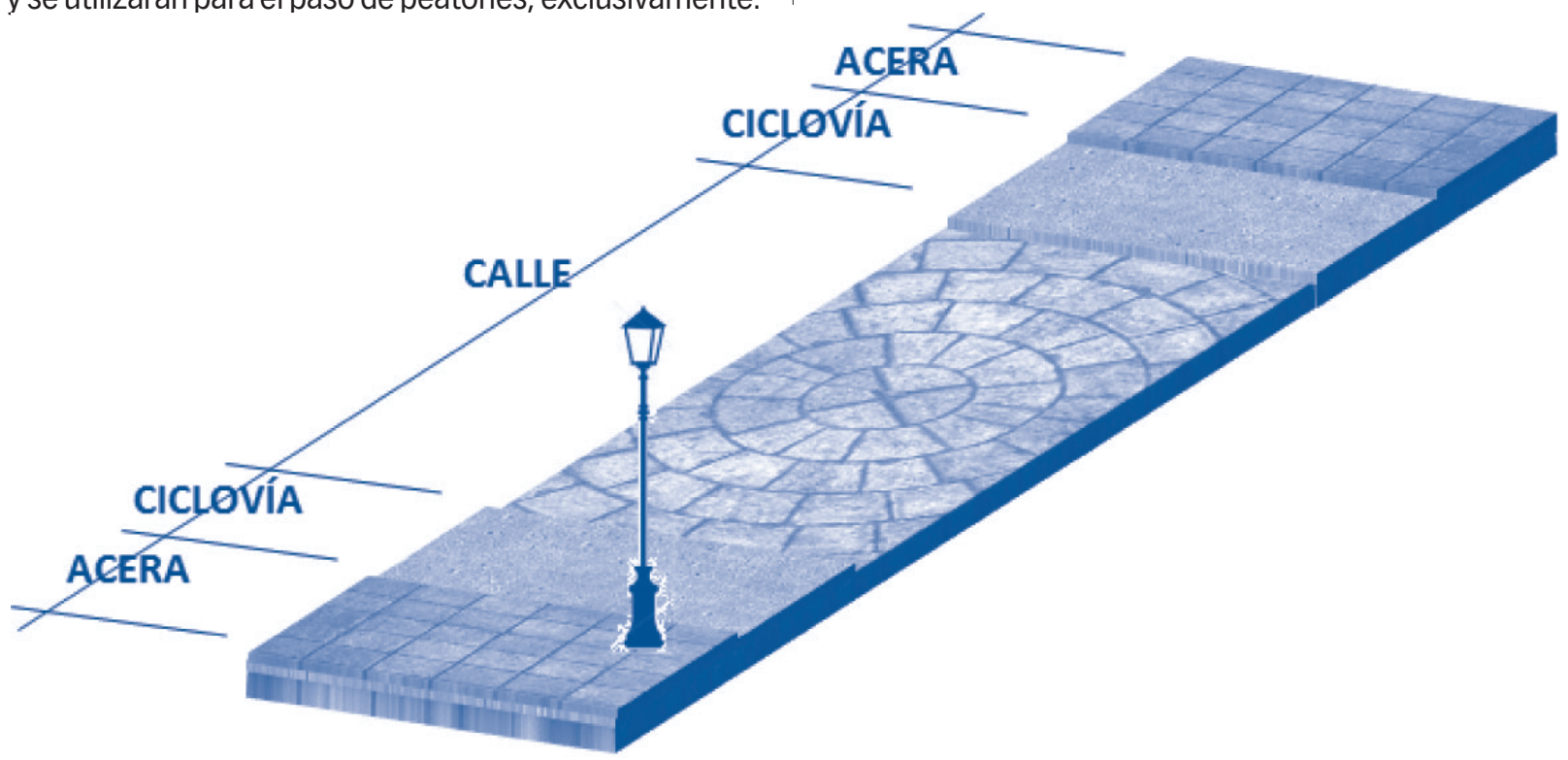

Figura 20.

Desarrollo de circulaciones por medio de texturas: acera, ciclo-vía y calle

Fuente: Elaboración propia.

Uno de los recursos más aprovechables en el casco urbano de Santa María Ostuma es el paisaje. Por un lado, la iglesia parroquial es un elemento con valor arquitectónico que predomina en el casco urbano; por otrolado, desde su parque
- Las calles y ciclo-vía, para vehículos; y, en períodos alternativos, para paso de peatones y bicicletas, respectivamente (figura 20 ).

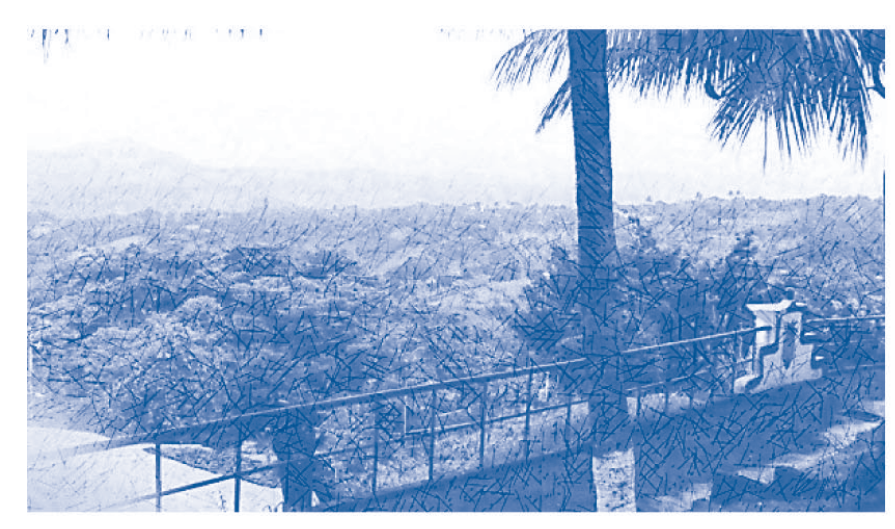

se observa el paisaje natural de los alrededores, teniendo una vista desde lo alto muy atractiva. La recomendación es mantenerlo libre de obstáculos, procurando que no se ubiquen elementos en el parque ni en las calles aledañas a la iglesia parroquial (figura 21).

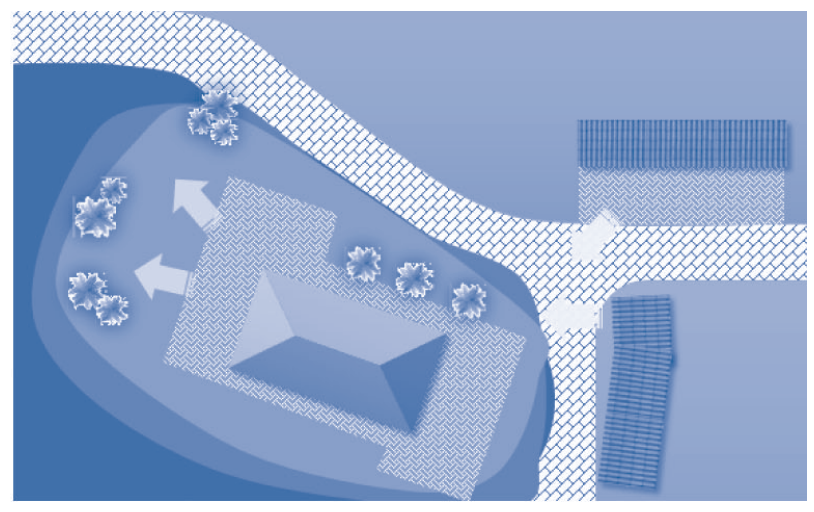

Figura 21.

Paisaje urbano

Fuente: Elaboración propia. Fotografía: Coralia Muñoz, Santa María Ostuma, La Paz, septiembre de 2014. 


\section{Jiquilisco, Usulután}

Jiquilisco es una ciudad de Usulután, en la zona oriental del país, cercana a las costas, por lo que su geografía es bastante llana. Se encuentra a pocos minutos de la bahía de Jiquilisco, un destino turístico de gran belleza natural y con cierta infraestructura para recibir visitantes. Sin embargo, la ciudad no aprovecha dicho potencial comercial debido a que carece de infraestructura. Su casco urbano muestra la estructura típica de iglesia, parque, edificios municipales y portales comerciales (figura 22).

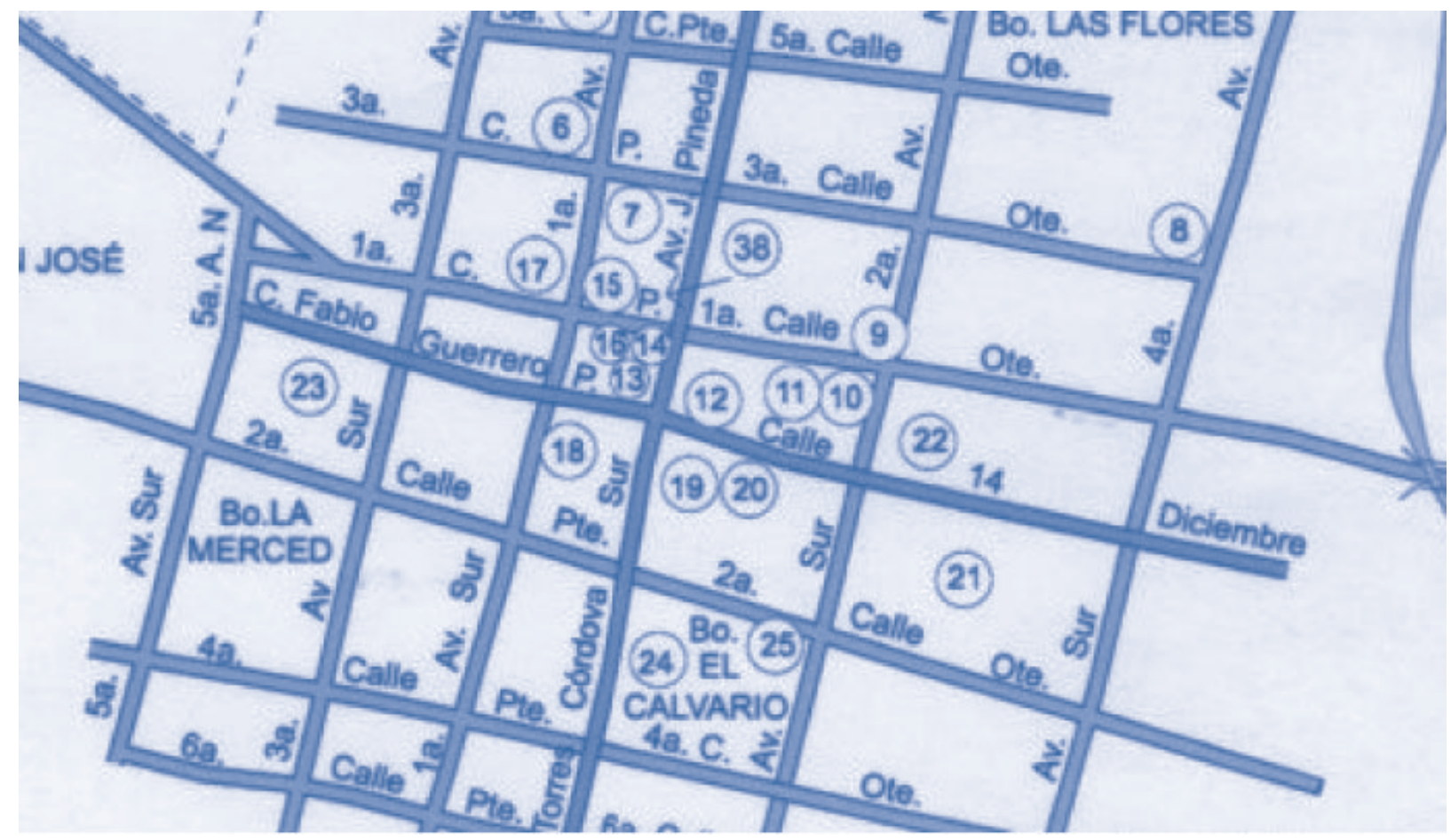

Figura 22.

Croquis de casco urbano de Jiquilisco

Fuente: Centro Nacional de Registros de El Salvador.

El casco urbano cuenta con el parque "Roberto Edmundo Canessa", pero presenta cierto deterioro. Alrededor del parque se encuentran locales comerciales, también deteriorados; algunos cerrados. También existe el edificio de un antiguo cine, que podría tener cierto valor patrimonial pero que también está abandonado (figura 23). 

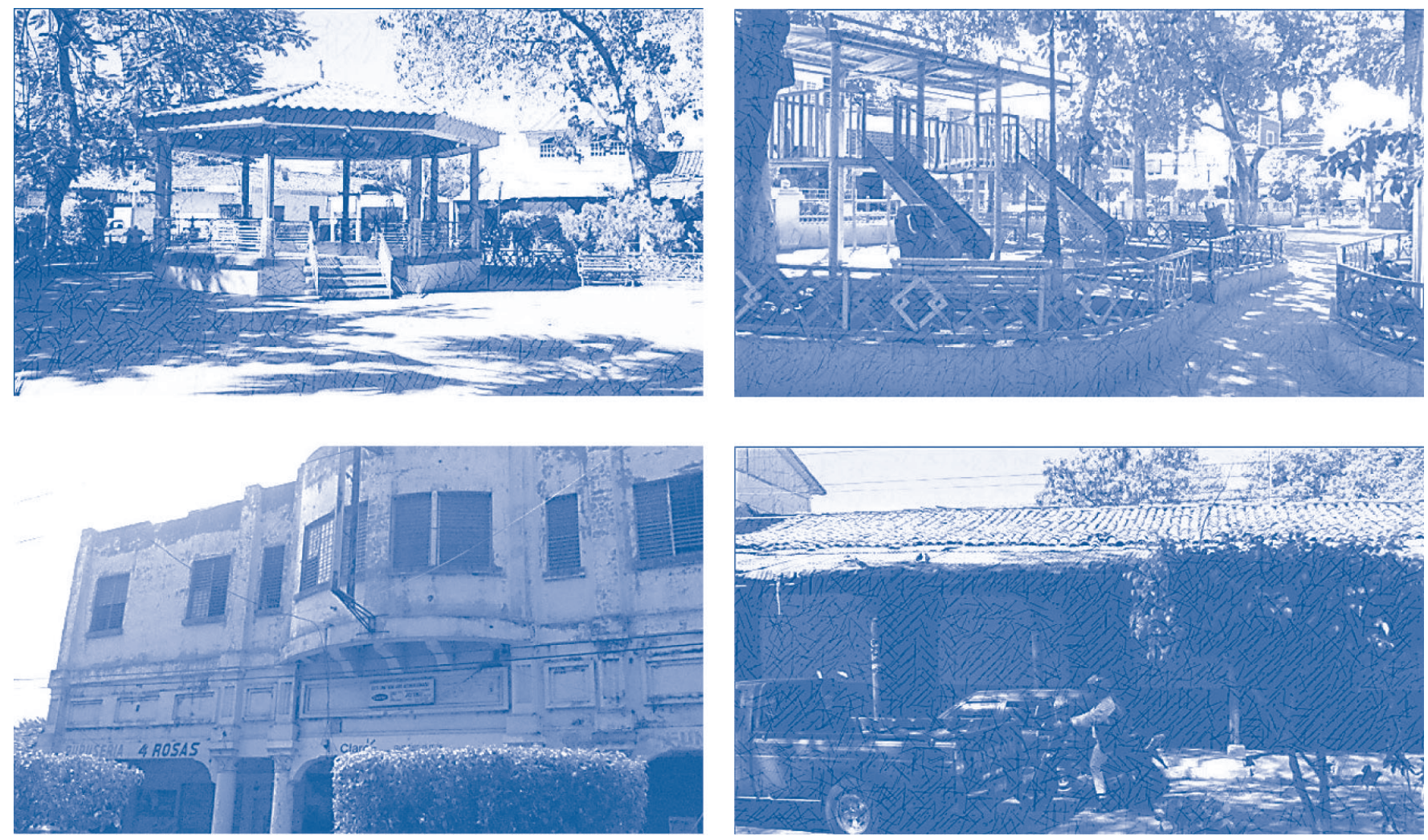

Figura 23.

Parque "Roberto Edmundo Canessa", portales y edificio antiguo del cine

Fotografías: Coralia Muñoz, Jiquilisco, Usulután, septiembre de 2014.

Jiquilisco es una ciudad de la zona costera donde la pesca constituye una de sus actividades económicas principales. Los mariscos podrían ser una imagen y un elemento para atraer turismo que hasta el momento no se ha desarrollado en su máximo potencial, puesto que los mariscos se venden en el mercado en condiciones que no son las que más atraen al turista. La oferta de servicios turísticos en los alrededores de la bahía de Jiquilisco podría plantear cierta competencia, pero también el flujo de visitantes hacia esos lugares es una oportunidad que, de ser aprovechada, podría inyectar recursos económicos a la ciudad.

El logotipo que se ha elegido para el casco urbano representa a los mariscos, utilizando el gráfico de un camarón, como una de las especies que tiene una demanda importante en diferentes mercados. En el logotipo, el camarón forma la J inicial del nombre de la ciudad (figura 24). 


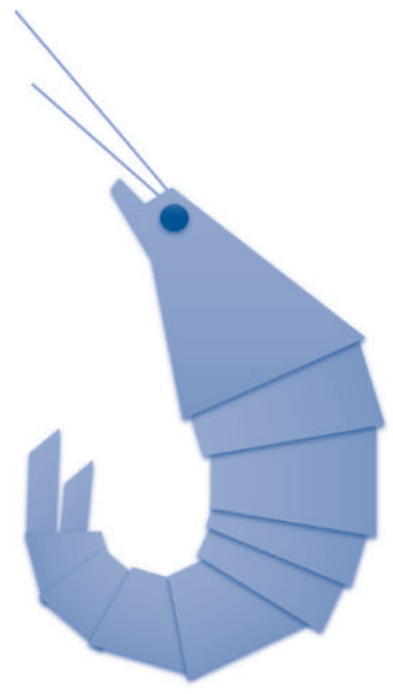

El diseño del casco urbano se muestra en la figura 25. En términos generales, se propone intervenir parte del área del parque para desarrollar en ella una plaza de mariscos donde se comercializarían los productos en dos estructuras octogonales que constituyen los quioscos de mariscos: una para el producto fresco y otra para el producto preparado, rodeadas de áreas con mesas.

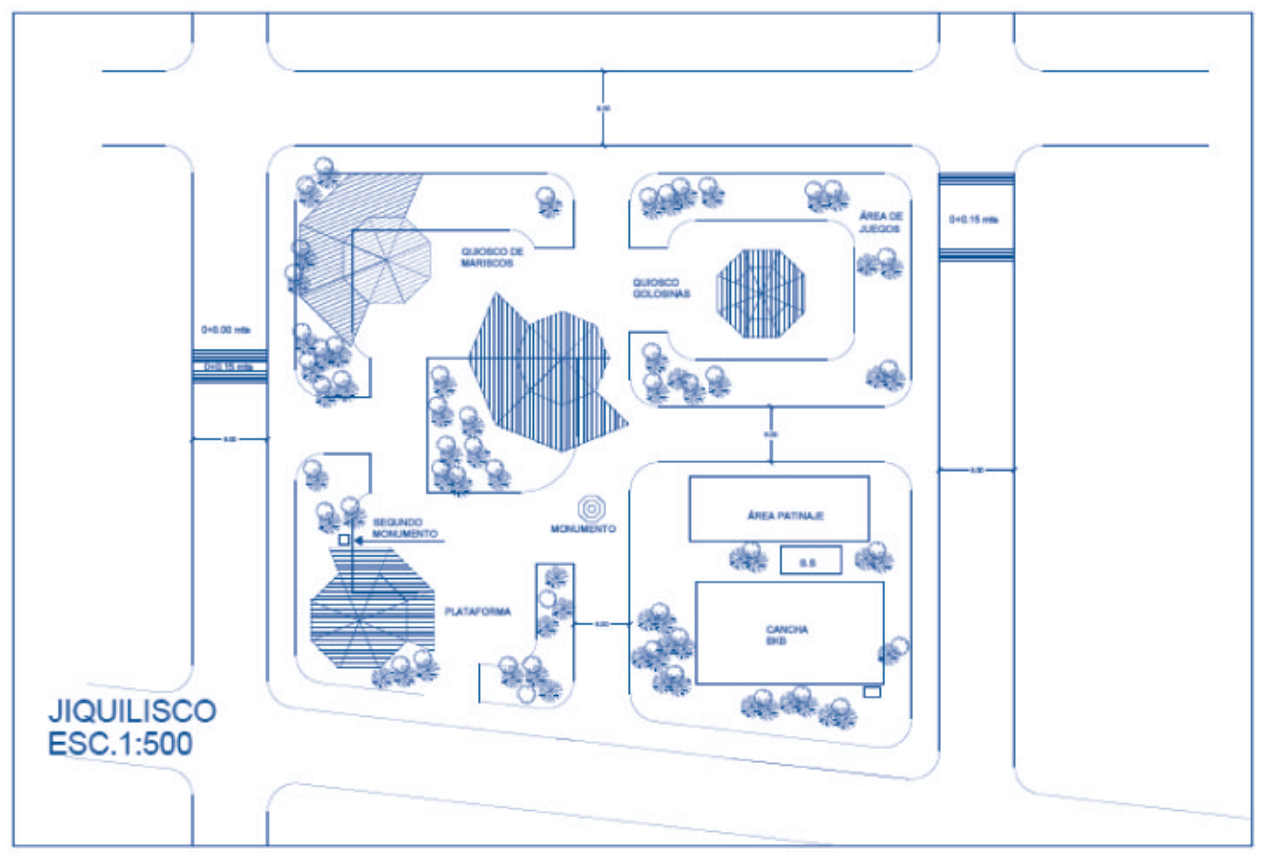

Figura 25.

Planta arquitectónica del casco urbano de Jiquilisco

Fuente: Elaboración propia. 
Los quioscos de mariscos son estructuras octogonales con techo de teja, o simulación de teja, y columnas de madera, con un área abierta para brindar servicio y una cerrada para almacenamiento de productos, o bien para la preparación de alimentos. Los quioscos funcionarían como una plaza de restaurantes donde hay locales para los diferentes negocios; y se comparte un área grande para las mesas y las sillas. Las diferencias entre el techo del quiosco y del alero pretende aprovechar los vientos dominantes para que puedan mitigar parcialmente el calor (figura 26).

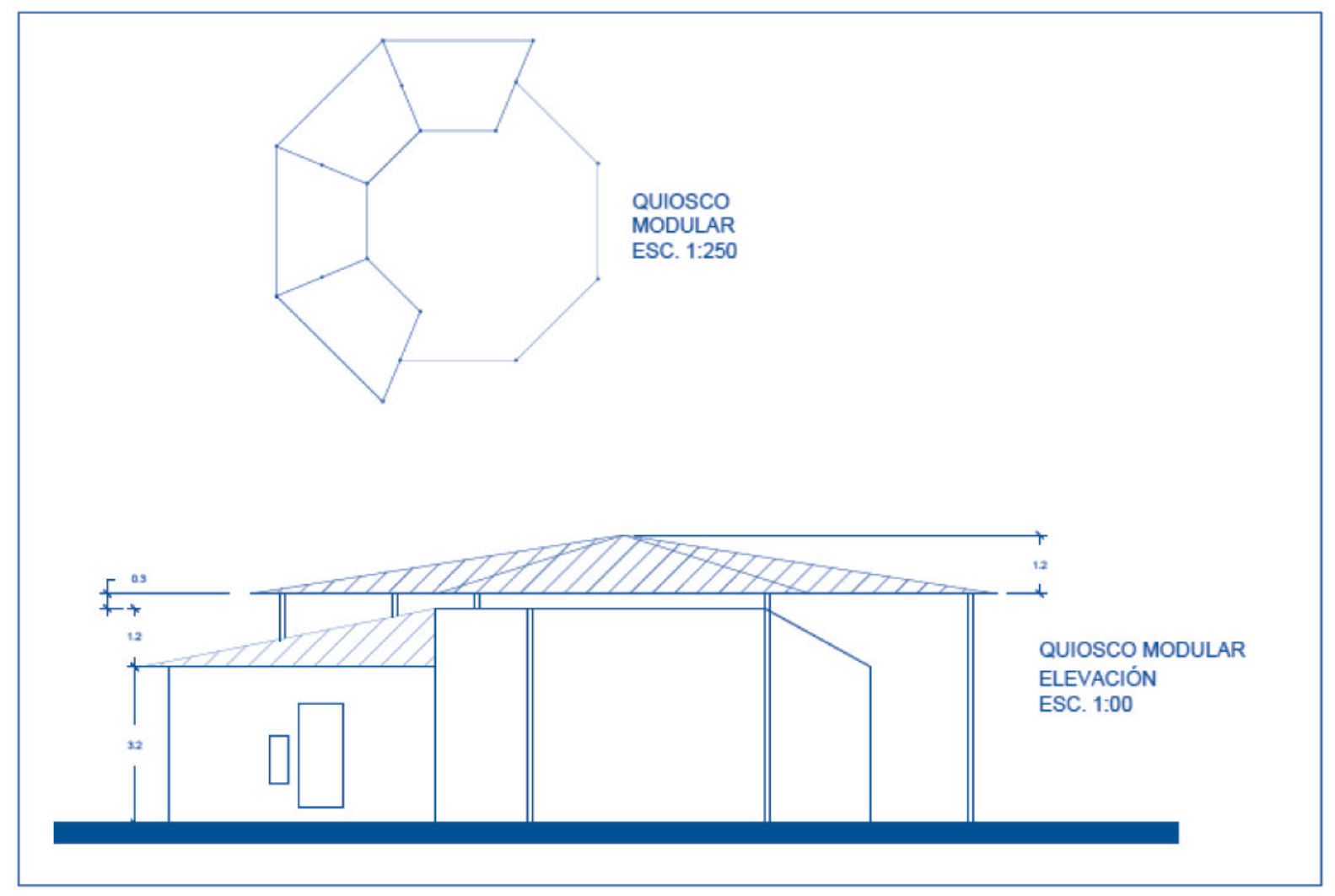

Figura 26.

Quiosco para plaza de mariscos

Fuente: Elaboración propia.

El quiosco de la figura 27 es un módulo que puede utilizarse también para el área de los juegos infantiles que, como puede apreciarse en la figura 25 , se ha modificado para ser un área que gira en torno a un quiosco de golosinas, el cual puede utilizarse para la venta de confitería, bebidas gaseosas, jugos y otros artículos relacionados preferidos por los niños. Una de las anteriores áreas de juego es utilizada para una pista de patinaje, con lo que se puede atraer a jóvenes que practican este deporte; solo se requeriría dejar el área con un pavimento de cemento afinado y colocar una rampa y un tubo para piruetas. Intencionalmente, el área de juegos infantiles está separada del área de patinaje y la cancha de basquetbol para dar su espacio a cada grupo de edad. Así mismo, en la figura 27 puede observarse que al actual quiosco del parque se le ha agregado el mismo tipo de alero que poseen los quioscos de mariscos para permitir que sea una plataforma desde la que puedan realizarse eventos como conciertos, teatro callejero u otros similares. 


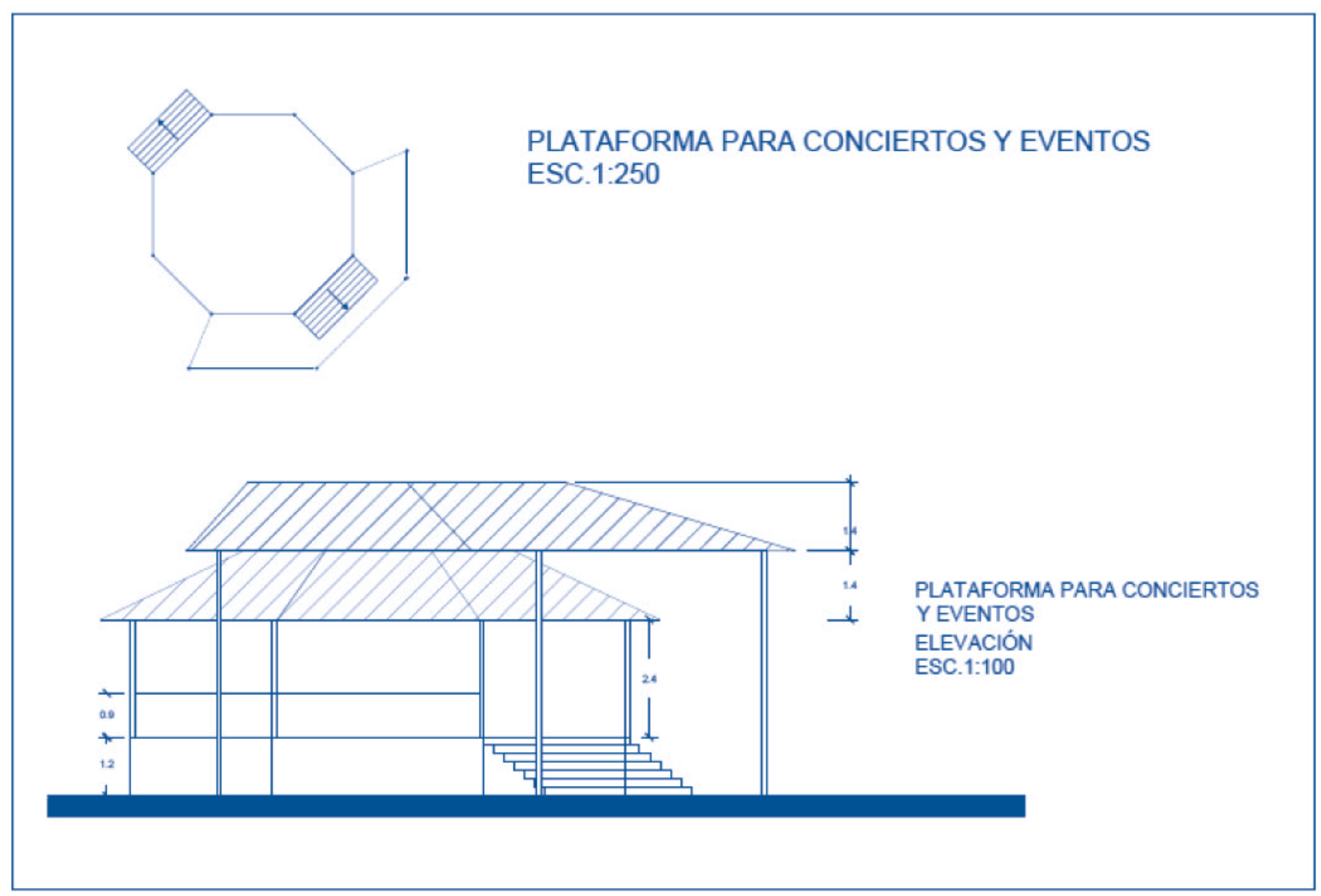

Figura 27.

Quiosco-plataforma para eventos culturales Fuente: Elaboración propia.

La propuesta incluye la plaza de mariscos y el quiosco de golosinas como principales generadores de ingresos económicos adicionales a la ciudad (figuras 25 y 26). Estos quioscos pueden ser administrados por la municipalidad y rentados a los empresarios de forma permanente, o bien como mercados itinerantes. Deben ser provistos de servicios de agua potable, alcantarillado y energía eléctrica.

La plaza de mariscos puede ofrecer, eventualmente, un espacio abierto para ubicar un mercado itinerante y ofrecer artesanías y otras comidas típicas. De ahí que las áreas de mesas puedan ser espacios flexibles, donde el mobiliario urbano no debería estar anclado al suelo, por lo menos, no permanentemente. Del mismo modo, las vías vehiculares alrededor del parque pueden valorizarse con texturas y restringir el paso de vehículos, de manera que en ellas puedan desarrollarse mercados itinerantes.
La atracción de visitantes no puede provenir del diseño urbano por sí solo, sino que debe haber un esfuerzo conjunto de la municipalidad, entidades gubernamentales y empresarios. Así mismo, la municipalidad que apoye esta iniciativa debería crear incentivos fiscales para aquellos que inviertan en esta parte de la ciudad, de manera que se pueda atraer de nuevo las franquicias que se trasladaron a ciudades cercanas y que han privado a los usuarios de sus bienes y servicios.

Debe considerarse que en esta ciudad la circulación vehicular está sujeta a congestionamientos, por lo que la regulación y organización del tráfico es fundamental para que comience a funcionar ordenadamente. Se recomienda que se considere establecer un solo sentido en torno al parque "Roberto Edmundo Canessa" y restringir el estacionamiento de vehículos por períodos 0 permanentemente (figura 28). 

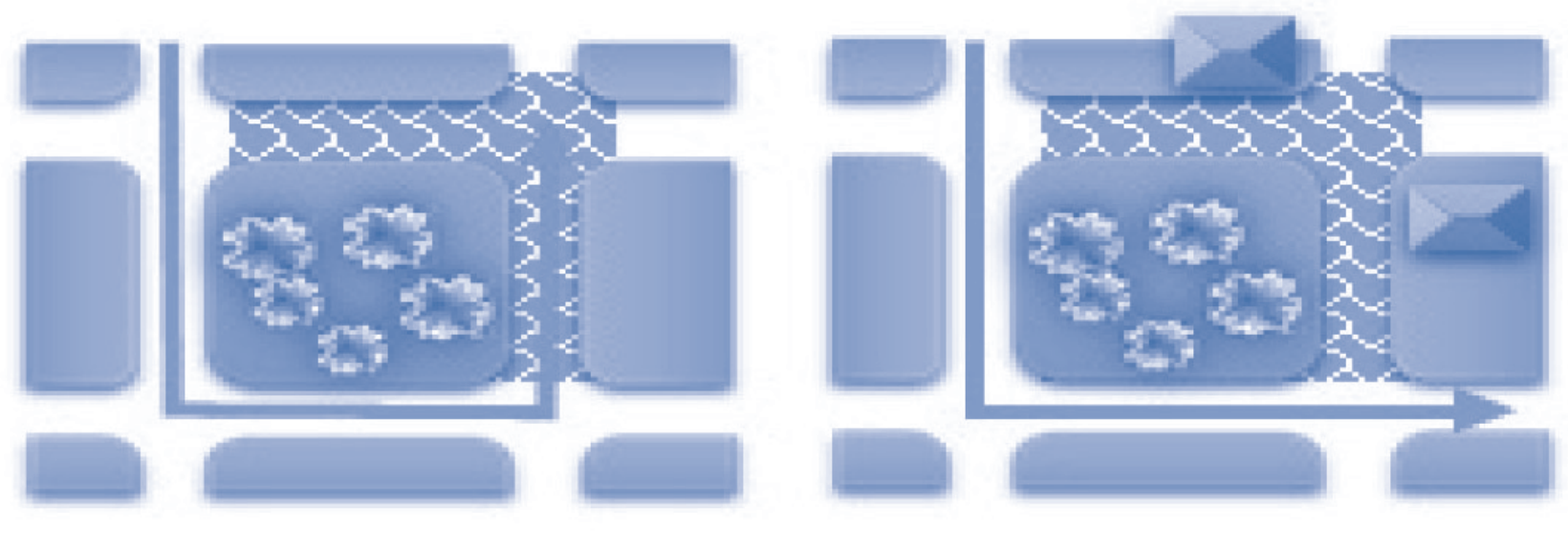

Figura 28.

Propuesta de organización del tráfico vehicular Fuente: Elaboración propia

La movilidad peatonal puede desarrollarse sobre la Avenida "Rubén Torres Córdova" Sur y la Calle "Fabio Guerrero" Poniente, utilizando texturas especiales para el pavimento. De ese modo, se crearía un solo ambiente con el edificio de la alcaldía municipal y la iglesia "Tránsito de María". Para eventos especiales, se restringiría el paso de vehículos sobre las vías mencionadas, en las que se pueden realizar mercados itinerantes.
Las aceras del parque poseen suficiente ancho para que la circulación de peatones sea cómoda. Los portales, por su lado, han sustituido totalmente a las aceras; y aunque ofrecen un espacio con sombra para caminar, están deteriorados. Es necesario que sean remodelados para mejorar la experiencia del usuario en dichos espacios, valorizando sus pisos y techos y restaurando las columnas y los detalles en madera que poseen (figura 29).

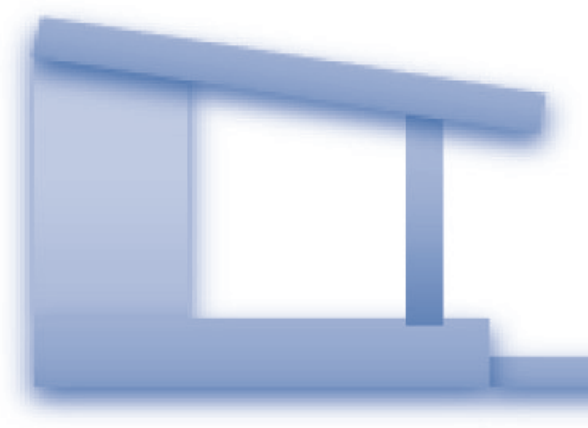

Mejoramiento de portales alrededor del parque

Figura 29.

Fuente: Elaboración propia
El mobiliario urbano debe estar acorde con la imagen que se ha elegido para el casco urbano. Estos elementos deben ser de estilo similar al de los portales; pueden estar elaborados con madera o metal, con detalles como frisos y frontones clásicos. El objetivo es brindarle unidad a todo el conjunto. Las bancas, luminarias y basureros del parque deben ser renovados, y en ellos pueden aplicarse las sugerencias de la figura 30, donde se han combinado elementos de metal y madera (o simulación de madera para evitar daños al medio ambiente) con elementos relacionados con el logotipo propuesto. 

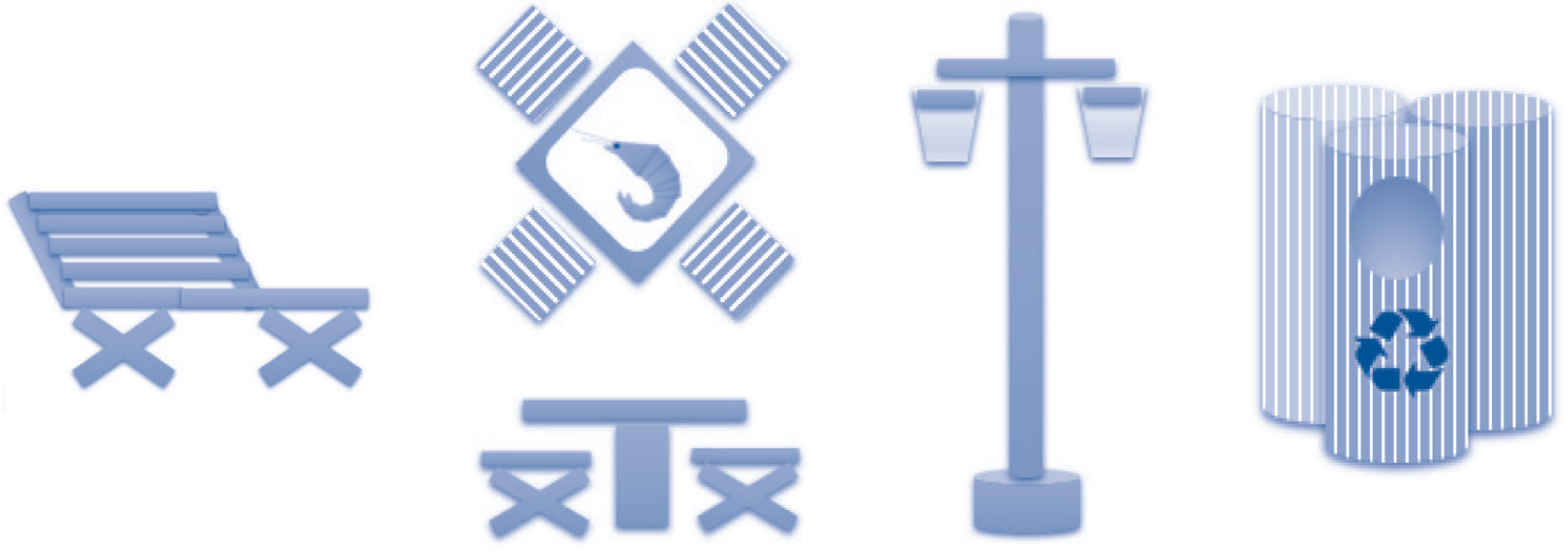

Figura 30.

Mobiliario urbano propuesto: bancas, mesas, luminarias y basureros

Fuente: Elaboración propia

\section{Enfoque ambiental del modelo}

Para cada una de las propuestas se plantean recomendaciones orientadas a la protección de los recursos ambientales. Entre otras se han considerado las siguientes:

- Conservar los árboles y áreas verdes disponibles 0 ampliarlas, combinándolas con texturas que permitan la filtración de agua.

- Aprovechar los vientos dominantes y la vegetación, hasta donde sea posible, para refrescar los espacios sin tener que recurrir a estructuras constructivas.

- Implantar o continuar con el proceso para reciclar basura, el cual no solo debe incluir la ubicación de basureros que permitan la clasificación de los desperdicios, sino buscar mayor eficiencia en la recolección y disposición final.

- Medir el nivel de consumo de energía del casco y buscar otras alternativas para reducir el consumo y hacerlo más eficiente.

- Instalar luminarias con lámparas ahorradoras de energía. Esto posiblemente tiene un costo de inversión mayor, pero se compensa con mayor tiempo de duración y menor consumo de energía eléctrica.

- En la medida de lo posible, considerar la promoción de uso de transporte alternativo como las bicicletas. Proveer al casco de ciclo-vías permite un atractivo de visita adicional y también la circulación sin contaminación ambiental.

\section{Conclusiones y recomendaciones}

El modelo propuesto se enfoca en la renovación del casco urbano, para que puedan aprovecharse las oportunidades de desarrollo local, específicamente en el ámbito comercial y turístico, en las que pueden participar diferentes sectores de la población, y en los que se han tomado en cuenta criterios de sostenibilidad y protección del medio ambiente.

Las condiciones de la propuesta se caracterizan por estar basadas en criterios de desarrollo urbano sostenible aplicados, que se espera puedan traer beneficios en el mediano y largo plazo al ser implantados en las ciudades donde pueda ponerse en marcha este proyecto.

Las tres ciudades en las que se ha aplicado el modelo poseen diferentes características en su ubicación geográfica, croquis urbano y potencial de desarrollo comercial y turístico. Sin embargo, ha sido posible desarrollar propuestas para cada una utilizando los recursos y criterios del modelo. Por lo tanto se puede concluir que el modelo es factible para ser aplicado en diferentes ciudades de municipios en El Salvador. 
Es importante considerar las siguientes recomendaciones:

- Aunque la aplicación del modelo es factible para diferentes ciudades, debe tomarse en cuenta que sus recursos resultan más provechosos en aquellos municipios que están geográficamente cercanos a rutas turísticas, o bien poseen destinos turísticos que generan flujo de visitantes.

- Del mismo modo, aunque el espacio ofrezca las facilidades para desarrollar el casco urbano, si no existen las actividades complementarias como las que aquí se plantean, la aplicación no será eficaz o el proyecto se estancará.

- Las iniciativas en el ámbito espacial deberán estar apoyadas por iniciativas a escala municipal, de ayuda financiera y por participación ciudadana.

- Solo así las ciudades que comiencen a modificarse, a partir de sus cascos urbanos, podrán alcanzar la sostenibilidad necesaria para ofrecer espacios vitales a las generaciones actuales y futuras.

- Por la naturaleza de los cambios y sugerencias de la aplicación del modelo, los gobiernos municipales y las entidades gubernamentales son las idóneas para recibir las propuestas de primera mano.

\section{Referencias}

Acuña, P.C. (21 de julio de 2012). Urbano Perú. Obtenido de Glosario de términos de zonificación: http:// urbanoperu.com/Glosario-de-terminos-dezonificacion

Bazant, J. (2003). Manual de diseño urbano. México: Editorial Trillas.
Corsini, J.M. (2007). Diseño urbano: accesibilidad y sostenibilidad. Barcelona: Industrias Gráficas Mármol.

Dreikon, C. (2014). Energía limpia en espacios públicos. San Salvador: PNUD / 2. ${ }^{\circ}$ Foro de Ciudades Sostenibles.

Garayo, S.G. (2012). www.lagenterula.files.wordpress.com. Obtenido de El modelo de desarrollo urbano reciente. "El modelo de desarrollo urbano reciente en el casco viejo de Vitoria" - Gasteiz: http://lagenterula.files. wordpress.com/2012/08/el-modelo-de-desarrollourbano-reciente-en-el-casco-viejo-de-gasteiz.pdf

Honles, G. (2014). "Urbanismo verde, hacia una ciudad sustentable. San Salvador": 2. Foro de Ciudades Sostenibles.

Martínez, P.Á. (2013). Obtenido de El paisaje urbano: http:// personales.alumno.upv.es/pabluma1/PABLO\%20 LUGO\%20archivos/EL\%2OPAISAJE_URBANO.pdf

Monje Álvarez, C.A. (2011). Metodología de la investigación cualitativa y cuantitativa. Neiva: Universidad Surcolombiana.

Naredo, J.M. (1996). "Sobre el origen, uso y contenido del término sostenible". Textos sobre sostenibilidad - Depto. Urbanística y Ordenación del Territorio, Universidad Politécnica de Madrid, 7-11.

Quiroa Laos, G. (2010). http://www.juridicas.unam.mx. Obtenido de "La administración de ciudades nuevas en México y otros países": http://www.juridicas.unam. $\mathrm{mx} /$ publica/librev/rev/gac/cont/2/cod/cod10.pdf

Secretaría de Asentamientos Humanos y Obras Públicas. (1978). www.hic-al.org. Obtenido de Glosario de Términos de Asentamientos Humanos México: http://www.hic-al.org/glosario_definicion.cfm?id_ entrada $=27$ 